\title{
Canopy effect caused by vapour transfer in covered freezing soils
}

\author{
S. ZHANG*, J. TENG*, Z. HE*, Y. LIU*, S. LIANG*, Y. YAO‡ and D. SHENG*†
}

\begin{abstract}
Canopy effect in this paper refers to the phenomenon whereby moisture accumulates underneath an impervious cover. Field observations reveal that the canopy effect can occur in relatively dry soils where the groundwater table is deep and can lead to full saturation of the soil immediately underneath the impervious cover. However, numerical analysis based on existing theories of heat and mass transfer in unsaturated soils can only reproduce a minor amount of moisture accumulation caused by an impervious cover, particularly when the groundwater table is relatively deep. In an attempt to explain the observed canopy effect in the field, this paper proposes a new mechanism of moisture accumulation in unsaturated freezing soils: vapour transfer in such a soil is accelerated by the process of vapour-ice desublimation. A new approach for modelling moisture and heat movements is proposed in which phase changes during the evaporation, condensation and desublimation of vapour flow are considered. A laboratory device is designed specifically to study vapour transfer in unsaturated freezing soils. The test results reveal that vapour transfer can lead to significant moisture and ice accumulation near the freezing end of a soil specimen. The computed results show that the proposed model can indeed reproduce the unusual moisture accumulation observed in relatively dry soils. The results also demonstrate that soil freezing fed by vapour transfer can result in a water content that is close to full saturation. Because vapour transfer is seldom considered in geotechnical design, the canopy effect deserves greater attention during construction and earth works in cold and arid regions.
\end{abstract}

KEYWORDS: ground freezing; laboratory tests; numerical modelling; water flow

\section{INTRODUCTION}

Airfield runways in an airport in north-western China were reported to have experienced significant frost heave damage, with runways breaking down or even shattering at certain locations. A weak zone of subgrade soil was found to have formed along the centreline of the runway, where the water content was observed to be close to full saturation ( $\mathrm{Li}$ et al., 2014). The airport is located in north-western China, which is characterised by its cold and arid climate. The typical annual precipitation in this region can be as low as $328 \mathrm{~mm}$, and the annual evaporation can be as high as $1438 \mathrm{~mm}$. Moisture accumulation due to rainwater infiltration was considered unlikely because the pavement was essentially intact and impervious during the previous rainy season (summer). The annual minimum and maximum temperatures are approximately $-20^{\circ} \mathrm{C}$ and $35^{\circ} \mathrm{C}$, respectively. The groundwater table is more than $20 \mathrm{~m}$ deep, eliminating the possibility of capillary action influencing the water content of the surface soil. The question is then, where is the water in the subgrade soil coming from?

According to Li et al. (2014), the pavement acts as a 'pot cover' and prevents evaporation, leading to moisture accumulation under the pavement. They used the terminology of 'pot cover effect' to reflect the fact that the moisture migration was driven by a temperature gradient in the ground and was prevented by an impervious cover. However, as will be shown in this paper, this terminology does not represent what occurred under the airfield runway. The temperature

Manuscript received 18 January 2016; revised manuscript accepted 12 May 2016. Published online ahead of print 14 June 2016.

Discussion on this paper closes on 1 April 2017, for further details see p. ii.

* National Engineering Laboratory for High-Speed-Railway Construction, Central South University, Changsha, PR China.

$\dagger$ ARC Centre of Excellence in Geotechnical Science and Engineering, the University of Newcastle, Newcastle, NSW, Australia.

\$ School of Transportation Science and Engineering, Beihang University, Beijing, PR China. gradient alone cannot be the only driving force of the moisture accumulation. Some other mechanism that enables the moisture to accumulate must exist, most likely in the form of vapour transfer when the groundwater table is $20 \mathrm{~m}$ deep. The biological terminology of 'canopy effect' is borrowed in this paper to reflect the dual mechanisms of vapour transfer. The canopy effect in plant biology refers to the phenomenon where crowns of individual trees or forest act as a special layer of absorption for energy from sunlight and water from tree roots. Significant amounts of water are consequently stored in the tree leaves for photosynthesis. The paper will provide a more detailed justification for the use of this terminology to refer to the large amount of moisture accumulation under impervious covers.

The objective of this work is to demonstrate and reproduce the unusual canopy effect observed in relatively cold and dry soils. The paper is organised as follows. The following section presents the problem and attempts to explain the problem using existing theories and concepts in the literature. The limitations of existing theories are then demonstrated through numerical examples. The third section presents new concepts and a new model for vapour transfer in unsaturated freezing soils, in an attempt to theoretically reproduce the high moisture accumulation under an impervious cover. The effectiveness of the new model is demonstrated through numerical examples. Based on the new concepts proposed in the third section, a new experimental device is designed to reproduce the canopy effect in the laboratory in the fourth section. A series of laboratory tests are also conducted to validate the proposed model in the third section. Finally, some conclusions are drawn based on the numerical and experimental results and discussion.

\section{ANALYSIS OF CANOPY EFFECT USING EXISTING THEORIES \\ Canopy effect under impervious covers}

When a ground surface is covered by an impervious cover, as shown in Fig. 1, the moisture content profiles under the cover 


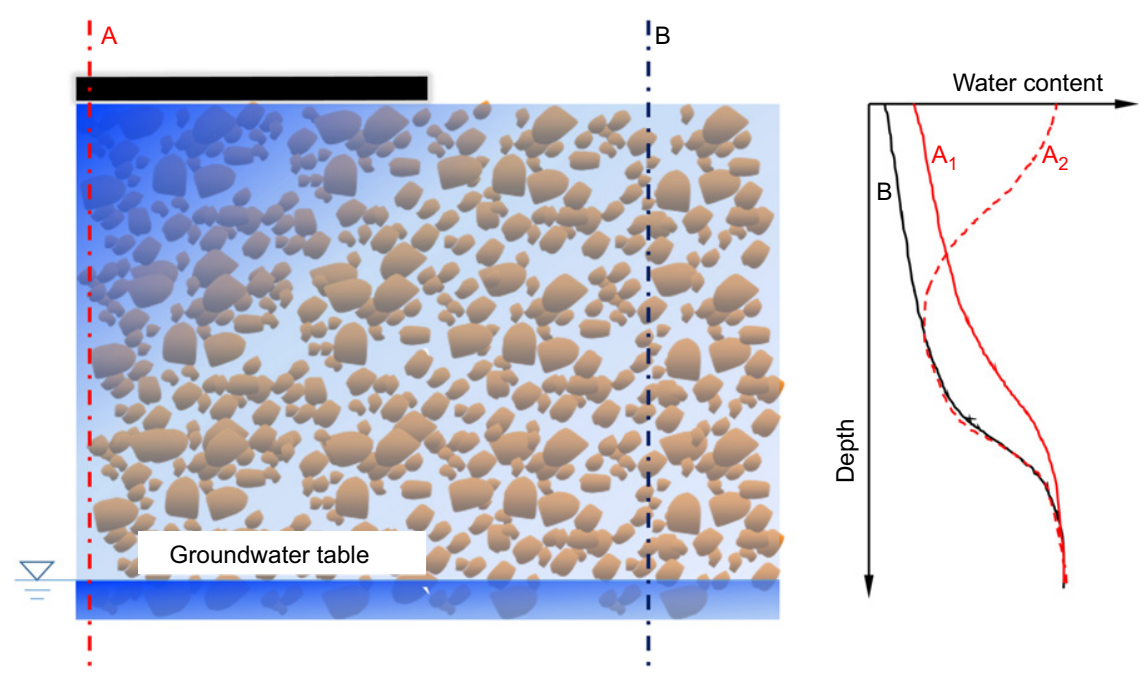

Fig. 1. Canopy effect underneath an impervious cover

(profile A) and outside the cover (profile B) will be different. In addition, two possible moisture profiles may exist under the impervious cover: profile $A_{1}$, for a relatively high groundwater table where capillary action is the dominant mechanism of moisture transfer, and profile $\mathrm{A}_{2}$, for a low groundwater table where vapour transfer is the dominant mechanism.

The occurrence of profile $A_{1}$ is straightforward, and indeed, the only difference between profile $A_{1}$ and profile $B$ is that the moisture content of the former is somewhat higher than the latter owing to the cover preventing evaporation. The occurrence of profile $A_{2}$ is, however, less straightforward and is seldom mentioned in the literature. The case reported by Li et al. (2014) refers to profile $\mathrm{A}_{2}$ in Fig. 1. Eigenbrod \& Kennepohl (1996) reported that significant moisture accumulation due to vapour transfer occurred underneath a road pavement and led to significant frost heave damage to the pavement. Because profile $A_{2}$ represents a deep groundwater table and a dry foundation soil, issues associated with high moisture content are more likely to be ignored in geotechnical design. Therefore, the situation of profile $A_{2}$ represents a significant threat to engineering practice and is referred to as the canopy effect in this paper. The main objective here is to reveal the true physical mechanism of profile $\mathrm{A}_{2}$ and to reproduce it by way of numerical modelling and laboratory experiments.

\section{Mathematical model}

The theory of coupled moisture and heat transfer in unsaturated soils was pioneered by Philip \& de Vries (1957), who developed a mathematical model to describe the coupled movement of liquid water and water vapour under nonisothermal conditions (referred to as the PDV model). Milly (1984) adopted the matric head instead of the total volumetric water content in the PDV model. Nassar \& Horton (1989) further extended Milly's work by including osmotic effects on liquid and water vapour movement. Sakai et al. (2009) presented a coupled model for water and vapour movement that considers condensation and evaporation effects under non-isothermal and low-water-content conditions. Particularly for modelling vapour transfer in unsaturated soils, Blight (1971), Fredlund \& Rahardjo (1993) and Or et al. (2013) adopted a modified Fick's law and defined the diffusion coefficient. Philip \& de Vries (1957) have shown that, at intermediate water contents, vapour flux is enhanced, that is, greater than that predicted by Fick's Law. To account for this phenomenon, 'enhancement factors' were introduced that account for the effects of thermal gradients on water vapour diffusion. On the basis of the enhancement factors defined by Cass et al. (1984), Saito et al. (2006) developed a model for simulating vapour transfer. In addition, Zeng et al. (2011) divided the vapour flow into three routes: vapour diffusion, vapour convection and vapour dispersion, and defined the individual transfer coefficients for these three routes; however, these coefficients cannot easily be determined.

In this paper, the approaches in Philip \& de Vries (1957) and Saito et al. (2006) are followed. The flow of liquid water and vapour in an unsaturated soil are driven either by a temperature gradient or by a matric head gradient, as follows

$$
\begin{aligned}
& q_{\mathrm{L}}=q_{\mathrm{L} h}+q_{\mathrm{L} T}=-K_{\mathrm{L} h}\left(\frac{\partial h}{\partial z}+1\right)-K_{\mathrm{L} T} \frac{\partial T}{\partial z} \\
& q_{\mathrm{v}}=q_{\mathrm{v} h}+q_{\mathrm{v} T}=-K_{\mathrm{v} h} \frac{\partial h}{\partial z}-K_{\mathrm{v} T} \frac{\partial T}{\partial z}
\end{aligned}
$$

where $q_{\mathrm{L} h}$ and $q_{\mathrm{L} T}$ are isothermal and thermal liquid water fluxes (m/s), respectively; $q_{\mathrm{v} h}$ and $q_{\mathrm{v} T}$ are isothermal and thermal vapour fluxes $(\mathrm{m} / \mathrm{s})$, respectively; $h$ is the water pressure head or the negative matric head $(\mathrm{m}) ; T$ is the temperature $(\mathrm{K})$; and $z$ is the spatial coordinate positive upward $(\mathrm{m}) . K_{\mathrm{L} h}(\mathrm{~m} / \mathrm{s})$ and $K_{\mathrm{L} T}\left(\left(\mathrm{~m}^{2} / \mathrm{K}\right) / \mathrm{s}\right)$ are the isothermal and thermal hydraulic conductivities for liquid water fluxes due to gradients in $h$ and $T$, respectively; and $K_{\mathrm{v} h}(\mathrm{~m} / \mathrm{s})$ and $K_{\mathrm{v} T}\left(\left(\mathrm{~m}^{2} / \mathrm{K}\right) / \mathrm{s}\right)$ are the isothermal and thermal vapour hydraulic conductivities, respectively.

Following mass conservation equation, the transient water content in soil can be expressed as

$$
\frac{\partial \theta}{\partial t}=\frac{\partial\left(\theta_{\mathrm{L}}+\theta_{\mathrm{v}}\right)}{\partial t}=-\frac{\partial q_{\mathrm{L}}}{\partial z}-\frac{\partial q_{\mathrm{v}}}{\partial z}
$$

where $\theta$ is the total water content $\left(\mathrm{m}^{3} / \mathrm{m}^{3}\right)$, which equals the summation of the liquid water content $\theta_{\mathrm{L}}\left(\mathrm{m}^{3} / \mathrm{m}^{3}\right)$ and the equivalent vapour content $\theta_{\mathrm{v}}\left(\mathrm{m}^{3} / \mathrm{m}^{3}\right)$; and $t$ is the time (s).

Substituting equations (1a) and (1b) into equation (2), leads to the governing equations for one-dimensional flow of liquid water and vapour in an unsaturated soil, which is a set of coupled non-linear partial differential equations

$$
\begin{aligned}
\frac{\partial \theta}{\partial t} & =\frac{\partial \theta_{\mathrm{L}}}{\partial t}+\frac{\partial \theta_{\mathrm{v}}}{\partial t} \\
& =\frac{\partial}{\partial z}\left[K_{\mathrm{L} h}\left(\frac{\partial h}{\partial z}+1\right)+K_{\mathrm{L} T} \frac{\partial T}{\partial z}+K_{\mathrm{v} h} \frac{\partial h}{\partial z}+K_{\mathrm{v} T} \frac{\partial T}{\partial z}\right]
\end{aligned}
$$


Table 1. Calculation of parameters used in the model

\begin{tabular}{l|l|l}
\hline Parameter & Equation & Resource \\
\hline Surface tension of liquid water, $\gamma: \mathrm{J} / \mathrm{m}^{2}$ & $\gamma=75 \cdot 6-0 \cdot 1425 T-2 \cdot 38 \times 10^{-4} T^{2}$ & Hillel (1971) \\
Saturated vapour density, $\rho_{\mathrm{vs}}: \mathrm{kg} / \mathrm{m}^{3}$ & $\rho_{\mathrm{vs}}=\exp \left(31 \cdot 37-6014 \cdot 79 T^{-1}-7 \cdot 92 \times 10^{-3} T\right) \times 10^{-3} T^{-1}$ & Hillel (1971) \\
Enhancement factor $\eta$ & $\eta=9 \cdot 5+3 \theta_{\mathrm{L}} \theta_{\mathrm{s}}^{-1}-8 \cdot 5\left\{1 / \mathrm{exp}\left[1+2 \cdot 6\left(f_{\mathrm{c}}\right)^{-0 \cdot 5} \theta_{\mathrm{L}} \theta_{\mathrm{s}}^{-1}\right]^{4}\right\}$ & Cass et al. $(1984)$ \\
Vapour diffusivity in air, $D_{\mathrm{a}}: \mathrm{m}^{2} / \mathrm{s}$ & $D_{\mathrm{a}}=2 \cdot 12 \times 10^{-5}(T / 273 \cdot 15)^{2}$ & Campbell (1985) \\
Latent heat of water vaporisation, $L_{\mathrm{w}}: \mathrm{J} / \mathrm{kg}$ & $L_{\mathrm{w}}=2 \cdot 501 \times 10^{6}-2369 \cdot 2 T$ & Sakai et al. (2009) \\
\hline
\end{tabular}

$f_{\mathrm{c}}$ is the mass fraction of clay in the soil.

Neglecting hysteresis between drying and wetting curves, the van Genuchten model (van Genuchten, 1980) is adopted to simulate the soil water characteristic curve (SWCC), as follows

$$
\Theta=\left[1+(-\alpha h)^{n}\right]^{-m}
$$

where $\Theta$ is the effective saturation (dimensionless) and $\Theta=\left(\theta_{\mathrm{L}}-\theta_{\mathrm{r}}\right) /\left(\theta_{\mathrm{s}}-\theta_{\mathrm{r}}\right)$, with $\theta_{\mathrm{s}}$ and $\theta_{\mathrm{r}}$ being the saturated and residual water content $\left(\mathrm{m}^{3} / \mathrm{m}\right)$, respectively; $\alpha\left(\mathrm{m}^{-1}\right)$, $n$ (dimensionless) and $m(=1-1 / n)$ are empirical shape parameters. While different functions for the unsaturated hydraulic conductivity are available in the literature, the model proposed by Mualem (1976) is more widely adopted. The main advantage of Mualem's model is that it is based on a SWCC model and hence uses the same parameters as in the SWCC equation. The isothermal unsaturated hydraulic conductivity of liquid water is expressed as follows

$$
K_{\mathrm{L} h}=K_{\mathrm{s}} \Theta^{l}\left[1-\left(1-\Theta^{1 / m}\right)^{m}\right]^{2}
$$

where $K_{\mathrm{s}}$ is the saturated hydraulic conductivity $(\mathrm{m} / \mathrm{s})$; and $l$ is a fitting parameter and was set to 0.5 by Mualem (1976). The definitions of thermal hydraulic conductivity of liquid water $K_{\mathrm{L} T}$, and hydraulic conductivities of vapour due to temperature $K_{\mathrm{v} T}$, and matric head $K_{\mathrm{v} h}$ refer to Saito et al. (2006)

$$
\begin{aligned}
& K_{\mathrm{L} T}=K_{\mathrm{L} h}\left(h G_{\mathrm{w} T} \frac{1}{\gamma_{0}} \frac{\mathrm{d} \gamma}{\mathrm{d} T}\right) \\
& K_{\mathrm{v} h}=\frac{D}{\rho_{\mathrm{w}}}\left(\rho_{\mathrm{vs}} \frac{M g}{R T} H_{\mathrm{r}}\right) \\
& K_{\mathrm{v} T}=\frac{D}{\rho_{\mathrm{w}}} \eta H_{\mathrm{r}}\left(\frac{\mathrm{d} \rho_{\mathrm{vs}}}{\mathrm{d} T}\right)
\end{aligned}
$$

In equation (6), $G_{\mathrm{w} T}$ is the gain factor which amends the temperature dependence of the SWRC; $\gamma$ is the surface tension of soil water $\left(\mathrm{J} / \mathrm{m}^{2}\right)$; and $\gamma_{0}$ is the surface tension at $25^{\circ} \mathrm{C}\left(=71.89 \mathrm{~g} / \mathrm{s}^{2}\right)$. In equations (7) and (8), $M$ is the molecular weight of water $(=0.018 \mathrm{~kg} / \mathrm{mol}) ; \boldsymbol{g}$ is the gravitational acceleration $\left(\mathrm{m} / \mathrm{s}^{2}\right) ; R$ is the universal gas constant $(=8 \cdot 341(\mathrm{~J} / \mathrm{mol}) / \mathrm{K}) ; H_{\mathrm{r}}$ is the relative humidity (dimensionless); $\eta$ is an enhancement factor (dimensionless) (Cass et al., $1984) ; \rho_{\mathrm{vs}}$ is the saturated vapour density $\left(\mathrm{kg} / \mathrm{m}^{3}\right)$; and $\rho_{\mathrm{w}}$ is the liquid water density $\left(=1000 \mathrm{~kg} / \mathrm{m}^{3}\right)$. Parameter $H_{\mathrm{r}}$ relates vapour density to matric head and temperature and is expressed as follows

$$
H_{\mathrm{r}}=\exp \left(\frac{h M \boldsymbol{g}}{R T}\right)
$$

$D$ in equations (7) and (8) is the vapour diffusivity in soil $\left(\mathrm{m}^{2} / \mathrm{s}\right)$; it can be derived from the diffusivity of water vapour in air, as follows

$$
D=\tau \theta_{\mathrm{a}} D_{\mathrm{a}}=\frac{\theta_{\mathrm{a}}^{7 / 3}}{\theta_{\mathrm{s}}^{2}} \theta_{\mathrm{a}} D_{\mathrm{a}}
$$

where $\tau$ is the tortuosity factor, $\theta_{\mathrm{a}}$ is the air-filled porosity $\left(\mathrm{m}^{3} / \mathrm{m}^{3}\right), D_{\mathrm{a}}$ is the diffusivity of water vapour in air $\left(\mathrm{m}^{2} / \mathrm{s}\right)$.

Using the definition of relative humidity $H_{\mathrm{r}}$, the equivalent vapour content $\theta_{\mathrm{v}}$ in equation (2) can be determined as

$$
\theta_{\mathrm{v}}=\rho_{\mathrm{vs}} H_{\mathrm{r}} \frac{\theta_{\mathrm{s}}-\theta_{\mathrm{L}}}{\rho_{\mathrm{w}}}
$$

Definitions of other parameters used in this model can be found in Table 1, which refers to Teng et al. (2015) and Zhang et al. (2016a, 2016b).

Considering vaporisation and condensation processes in unsaturated soil, the governing equation of heat conservation is given as (de Vries, 1958; Nassar \& Horton, 1992)

$$
\begin{aligned}
C_{\mathrm{p}} & \frac{\partial T}{\partial t}+L_{\mathrm{w}} \rho_{\mathrm{w}} \frac{\partial \theta_{\mathrm{v}}}{\partial t} \\
& =\frac{\partial}{\partial z}\left[\lambda(\theta) \frac{\partial T}{\partial z}\right]-C_{\mathrm{L}} \frac{\partial q_{\mathrm{L}} T}{\partial z}-L_{\mathrm{w}} \rho_{\mathrm{w}} \frac{\partial q_{\mathrm{v}}}{\partial z}-C_{\mathrm{v}} \frac{\partial q_{\mathrm{v}} T}{\partial z}
\end{aligned}
$$

where $C_{\mathrm{p}}$ is defined as the sum of the volumetric heat capacity of the unsaturated soil $\left(\left(\mathrm{MJ} / \mathrm{m}^{3}\right) / \mathrm{K}\right)$ and is equal to the volumetric average of the solid $\left(C_{\mathrm{n}}=1.92\left(\mathrm{MJ} / \mathrm{m}^{3}\right) / \mathrm{K}\right)$, liquid $\left(C_{\mathrm{L}}=4 \cdot 18\left(\mathrm{MJ} / \mathrm{m}^{3}\right) / \mathrm{K}\right)$, and air $\left(C_{\mathrm{v}}=6 \cdot 3\left(\mathrm{~kJ} / \mathrm{m}^{3}\right) / \mathrm{K}\right)$ phases (de Vries, 1958); $L_{\mathrm{w}}$ is the latent heat of water vaporisation $\left(\mathrm{J} / \mathrm{m}^{3}\right)$ as defined in Table 1 ; and $q_{\mathrm{L}}$ and $q_{\mathrm{v}}$ are the liquid water flux and vapour flux, respectively $(\mathrm{m} / \mathrm{s}) . \lambda(\theta)$ is the soil thermal conductivity $((\mathrm{W} / \mathrm{m}) / \mathrm{K})$. Several equations are available in the literature for describing $\lambda(\theta)$, such as Campbell (1985), Chung \& Horton (1987), and so on. The model by Chung \& Horton (1987) is employed here, because of its relatively fewer parameters

$$
\lambda(\theta)=b_{1}+b_{2} \theta_{\mathrm{L}}+b_{3} \theta_{\mathrm{L}}^{0.5}
$$

where $b_{1} \quad(=0 \cdot 228(\mathrm{~W} / \mathrm{m}) / \mathrm{K}), \quad b_{2} \quad(=-2 \cdot 406(\mathrm{~W} / \mathrm{m}) / \mathrm{K})$, and $b_{3} \quad(=4.909(\mathrm{~W} / \mathrm{m}) / \mathrm{K})$ are empirical regression parameters.

\section{Numerical implementation}

Equations (3) and (12) are highly non-linear because the parameters in these equations vary with time and the primary variables. The governing equations, combined with appropriate initial and boundary conditions, are solved numerically using the finite-element method for spatial discretisation and the finite-difference method for temporal discretisation. The solution procedure is facilitated by the Comsol Multiphysics package (5.0). The governing 
equations in Comsol Multiphysics can be expressed in the following form

$$
d_{\mathrm{a}} \frac{\partial \kappa}{\partial t}+\nabla \cdot \boldsymbol{\Gamma}=f
$$

where $\kappa$ is the primary variable in the governing equations; $\kappa=\{\theta, T\}, d_{\mathrm{a}}$ is a damping coefficient; $\boldsymbol{\Gamma}$ is the flux vector; and $f$ is the source term.

The generalised solution to equation (14) is given in the form

$$
\left(d_{\mathrm{a}} \frac{\partial \kappa}{\partial t}, \bar{\kappa}\right)_{\Omega}+(\nabla \cdot \boldsymbol{\Gamma}, \bar{\kappa})_{\Omega}=(f, \bar{\kappa})_{\Omega}
$$

where $\bar{\kappa}$ is the virtual primary variable. Equation (15) can be written as

$$
\left(d_{\mathrm{a}} \frac{\partial \kappa}{\partial t}, \bar{\kappa}\right)_{\Omega}-(\boldsymbol{\Gamma}, \nabla \bar{\kappa})_{\Omega}=(f, \bar{\kappa})_{\Omega}+(\boldsymbol{n} \cdot \boldsymbol{\Gamma}, \bar{\kappa})_{\partial \Omega}
$$

The time derivatives are discretised using the backward Euler difference method as follows

$$
\frac{\partial \kappa}{\partial t}=\frac{\kappa^{i}-\kappa^{i-1}}{\Delta t}
$$

where superscript $i$ refers to time $i ; \Omega$ is the domain of interest; $\partial \Omega$ is the boundary of the domain; and $\boldsymbol{n}$ is the outward norm vector of the boundary. Substituting equation (17) into equation (16) leads to the following equation

$$
\left(d_{\mathrm{a}} \frac{\kappa^{i}-\kappa^{i-1}}{\Delta t}, \bar{\kappa}\right)_{\Omega}-(\boldsymbol{\Gamma}, \nabla \bar{\kappa})_{\Omega}=(f, \bar{\kappa})_{\Omega}+(\boldsymbol{n} \cdot \boldsymbol{\Gamma}, \bar{\kappa})_{\partial \Omega}
$$

The steps above outline the solution procedure embedded in Comsol Multiphysics. To achieve numerical stability of the solution, the following strategies are adopted: the domain is divided into 10000 elements and the total time duration is divided into 12000 steps.

Similar results can also be obtained using commercial software such as Hydrus-1D. The Hydrus-1D program is a finite-element model for simulating one-dimensional movements of water, heat and multiple solutes in variably saturated media. The program numerically solves the Richards' equation for saturated-unsaturated water flow and Fickian-based advection dispersion equations for heat and solute transport. The model is supported by an interactive graphics-based interface for data-preprocessing, discretisation of the soil profile, and graphic presentation of the results (Šimůnek et al., 2013).

\section{Analysis of canopy effect}

The engineering background of the canopy effect has been given by Li et al. (2014). A concrete layer of $25 \mathrm{~cm}$ as the runway covers the original soil, which is a silt layer of more than $20 \mathrm{~m}$ thick. The silt belongs to an alluvial-pluvial deposit, a typical stratum in the Lanzhou area. The dry density of the silt is about $1.61 \mathrm{~g} / \mathrm{cm}^{3}$, liquid limit and plastic limit are $24 \cdot 8 \%$ and $15 \cdot 5 \%$, respectively. The SWCC and unsaturated hydraulic conductivity of the silty soil are given in Fig. 2, which were simulated by the van Genuchten (1980) model and the Mualem (1976) model, respectively.

To reveal the mechanism underlying the canopy effect, two cases are designed for computation, as presented in Table 2. A one-dimensional soil column, with a height of either $5 \mathrm{~m}$ or $20 \mathrm{~m}$, is chosen for the analysis. The water table is located at the bottom of the soil column, and the top boundary either has an evaporating flux $(10 \mathrm{~cm} /$ day $)$ or is completely

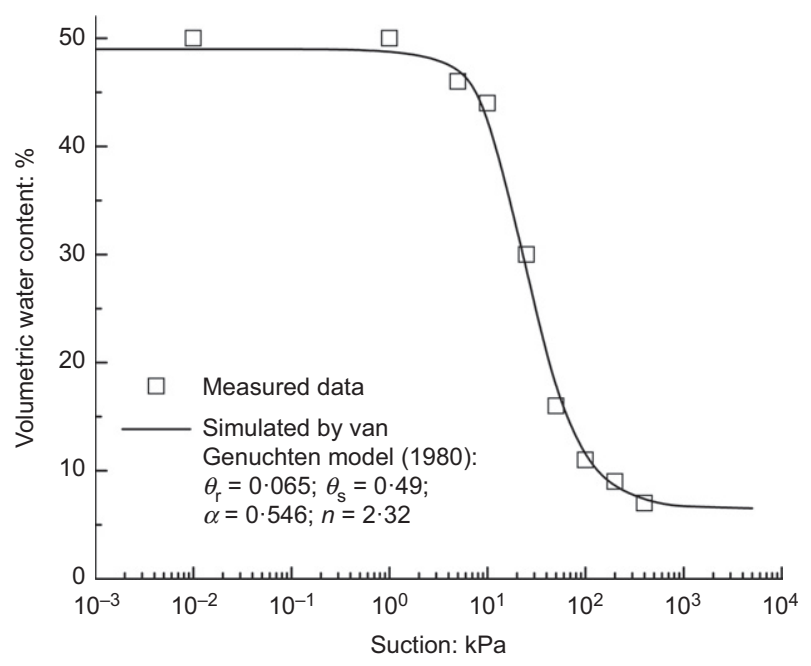

(a)

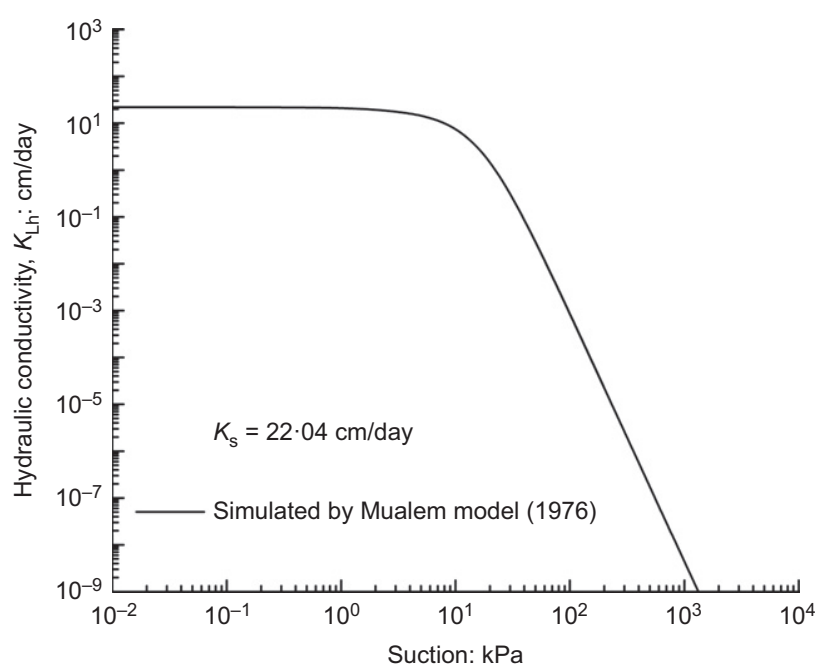

(b)

Fig. 2. SWCC and unsaturated hydraulic conductivity of silty soil in the Lanzhou area. Symbols represent measured data, and solid lines are the simulation results

sealed (zero flux). Two initial volumetric water contents are considered in this analysis: $7 \%$ and $20 \%$. A water content of $7 \%$ is slightly higher than the residual water content and represents an extremely dry condition; in addition, a water content of $20 \%$ is chosen for comparison and approximately locates at the intermediate value between saturated and residual water contents. The initial temperature along the soil profile is $15^{\circ} \mathrm{C}$. The top and bottom boundary temperatures are constantly maintained at $0^{\circ} \mathrm{C}$ and $15^{\circ} \mathrm{C}$, respectively, for a period of 90 days.

The computed results of case 1 are shown in Fig. 3. Figs 3(a) and 3(b) denote the groundwater table located at 5 and $20 \mathrm{~m}$, respectively. The impervious cover affects the moisture content to a depth of $20 \mathrm{~cm}$ when the groundwater table is located at $5 \mathrm{~m}$ and to a depth of $40 \mathrm{~cm}$ when the groundwater table is located at $20 \mathrm{~m}$. For the uncovered soil, the moisture content near the top surface does not decrease below the initial value, which is close to the residual moisture content. For the covered soil, the moisture content near the ground surface exhibited a minor increase of approximately $1.5 \%$, which is likely due to the vapour condensation at the top surface. The capillary rises in Figs 3(a) and 3(b) are approximately $4.0 \mathrm{~m}$. Moreover, the results computed by the Comsol-based program match quite well with those obtained 
Table 2. Initial and boundary conditions

\begin{tabular}{l|c|l|r|l}
\hline Case & Initial volumetric water content: $\%$ & Temperature boundary & Depth of water table: $\mathrm{m}$ & Water flow boundary \\
\hline 1 & 7 & Top: $0^{\circ} \mathrm{C} ;$ & 5 & 20 \\
2 & 20 & Bottom: $15^{\circ} \mathrm{C}$ & 5 & Top: uncovered/covered; \\
Bop: $0^{\circ} \mathrm{C} ;$ & Bottom: $15^{\circ} \mathrm{C}$ & Top: uncovered/covered; & Bottom: saturated \\
\hline
\end{tabular}

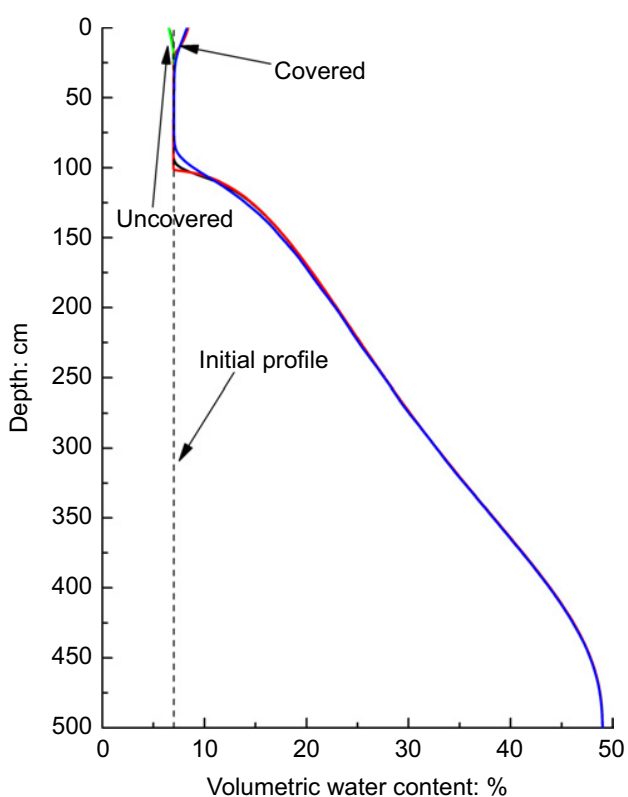

(a)

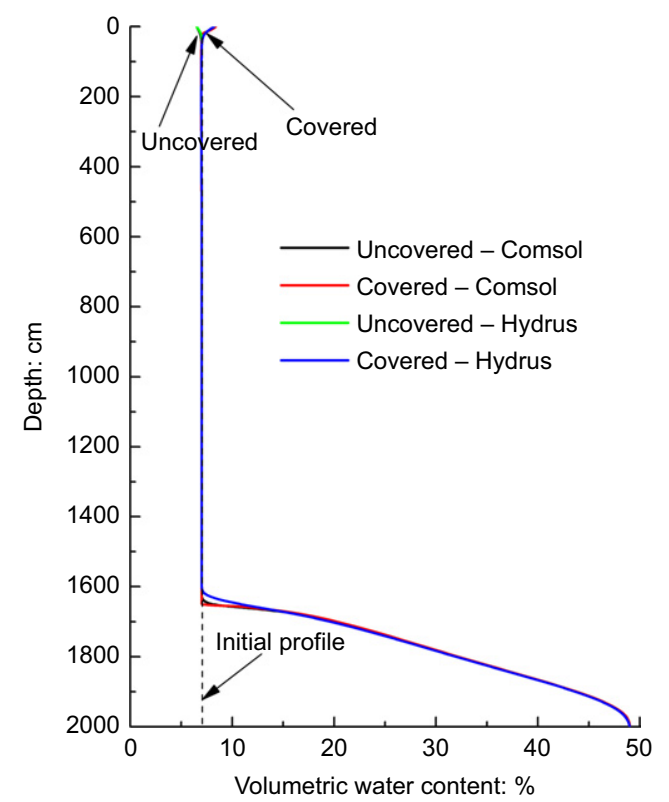

(b)

Fig. 3. Computed water content profiles at 90 days for case 1 , with water tables located at depths of (a) $5 \mathrm{~m}$ and (b) $20 \mathrm{~m}$

from Hydrus-1D, which acts as somewhat of a validation of the Comsol-based program in modelling coupled watervapour movement in unsaturated soils. The impervious cover seems to stop the evaporation at the ground surface but fails to accumulate significant moisture. The canopy effect reported in Li et al. (2014) is not apparent in this case.

Figure 4 shows the computed moisture profiles for a covered and uncovered soil with an initial water content of $20 \%$, namely, case 2. The figure shows that the depths from the top of $3.0 \mathrm{~m}$ and $5.0 \mathrm{~m}$ are influenced by the impervious cover for water tables at 5 and $20 \mathrm{~m}$, respectively. The maximum difference between the covered and uncovered moisture profiles is approximately $10 \cdot 5 \%$ of the volumetric water content, which occurs at the ground surface. It is also interesting to note that the moisture content underneath the cover does not increase above the initial value of $20 \%$, which is greater than the residual moisture content. However, no significant moisture accumulation is observed in this case either.

Test runs using the Comsol model and Hydrus-1D fail to reproduce a significant amount of moisture accumulation under impervious covers, which implies that existing models based on the PDV theory are incapable of generating the canopy effect of type $A_{2}$. A closer inspection of the PDV theory reveals its shortcomings. According to the PDV theory, liquid water flow and vapour flow are driven either by a matric suction gradient or by a temperature gradient. The vapour density is related to the matric suction and temperature through equation (9), and the matric suction is related to the moisture content by way of the SWCC (equation (4)). If evaporation is stopped by an impervious cover, or if vapour condenses into liquid water, the liquid water content in the soil increases, and the matric suction consequently decreases, which in turn increases the vapour density and reduces the moisture flow. Therefore, existing models based on the PDV theory predict an equilibrium state where moisture flow driven by temperature gradients in unsaturated soils is balanced by that driven by the suction gradient.

The cases analysed above are somewhat analogous to a cup of hot water covered by a cold ceramic lid. Some vapour condensation will occur at the cold ceramic lid; however, not much water will evaporate because the evaporation will stop when there is sufficient liquid water under the lid. However, the situation will change if the ceramic cover is replaced by a cover that absorbs water, for example, a cover made of dry wood. The water in the cup will transfer to the absorptive cover until it is fully saturated. The key question is then: what is the absorption mechanism for a moisture profile such as $\mathrm{A}_{2}$ shown in Fig. 1. The alternative question is: under what mechanism can the moisture content in the soil continue to increase without increasing the vapour density or decreasing matric suction?

\section{A NEW MECHANISM OF THE CANOPY EFFECT}

First it is noted that the two cases reported in the literature with significant moisture accumulation underneath impervious covers are both related to frozen soils (Eigenbrod \& Kennepohl, 1996; Li et al., 2014). Another inspirational example is that ice tends to grow continuously inside an old type of freezer (the non-frost-free type) as long as warm and humid air enters the freezer. Realising these facts, the authors propose a new mechanism for the canopy effect as follows.

When the temperature in a soil drops below the frost point, vapour under an impervious cover will change into ice through desublimation. The formation of ice will further reduce air humidity and increase the matric suction, which in 


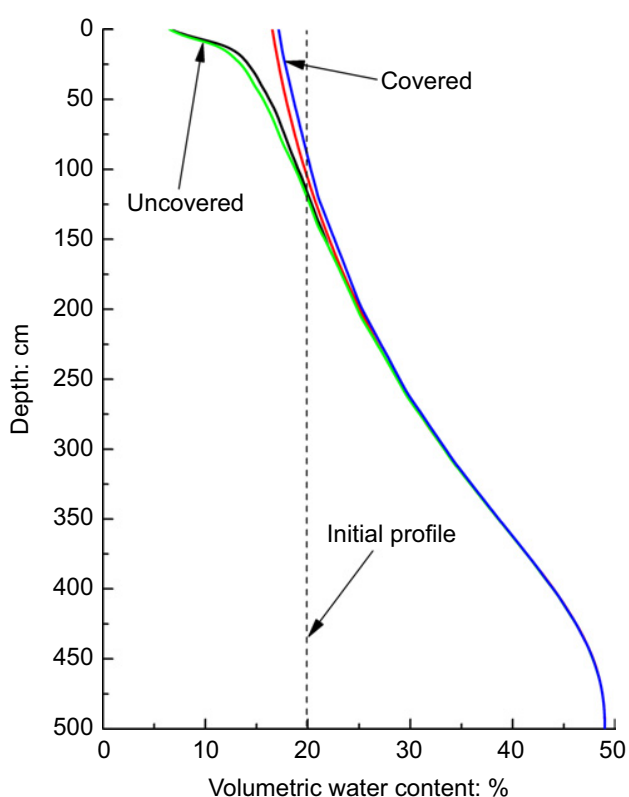

(a)

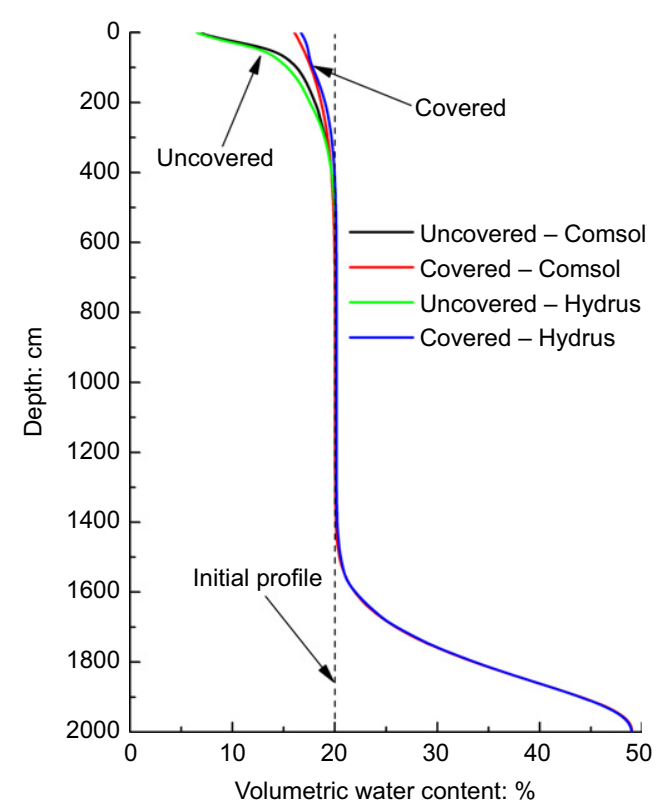

(b)

Fig. 4. Computed water content profiles at 90 days for case 2, with water tables located at depths of (a) $5 \mathrm{~m}$ and (b) $20 \mathrm{~m}$

turn accelerates vapour transfer in the soil. In other words, vapour-ice desublimation acts as a sink term in the moisture transfer equation and releases energy (latent heat) in the heat transfer equation. This process can lead to a significant accumulation of total water content (including ice) under the cover and possibly a moisture profile of type $\mathrm{A}_{2}$. The terminology 'canopy effect' is justified because of the absorption effect of the vapour-ice desublimation process.

In this section, a new theory is proposed that considers phase changes during evaporation, condensation and desublimation. Then, a specific laboratory experimental programme is introduced to validate the above mechanism.

\section{Theory for vapour transfer in unsaturated freezing soil}

Mathematical models for simulating heat and water flow in freezing soils have been proposed by Harlan (1973), Guymon \& Luthin (1974), Taylor \& Luthin (1978), Kung \& Steenhuis (1986), Hu et al. (1992), Zhou et al. (2014) and Zhang et al. (2016a, 2016b). Other theories also exist in the literature for water movement that leads to significant ice formation and volume increase of a freezing soil (frost heave), for example, the rigid ice model by Miller (1978) and the segregation potential theory by Konrad \& Morgenstern (1981). However, all these theories and models are based on liquid water movement and incapable of capturing the effect of an impervious cover. For example, in the rigid ice model and the segregation potential theory, it is the liquid water flow that is assumed to feed the ice formation and hence is the cause of frost heave. Such theories are not applicable to cases where the groundwater table is very deep and the soil is relatively dry. In these cases, vapour flow becomes important for the overall moisture transfer in soil (Eigenbrod \& Kennepohl, 1996; Guthrie et al., 2006; Sakai et al., 2009). On the other hand, theories of unsaturated soil seepage which usually consider vapour flow, mainly apply to soils with super-freezing temperatures (Philip \& de Vries, 1957; Milly, 1984; Nassar \& Horton, 1989; Wilson et al., 1994; Sakai et al., 2009; Cui et al., 2010; Teng et al., 2013, 2016), and few of these models are used for freezing soils where ice formation and frost heave may occur. Thus, a model for coupled liquid water, vapour and heat movements in unsaturated soils subjected to both sub- and super-freezing temperatures is not available in the literature. Such a model is proposed here to reproduce the canopy effect observed in the field.

Under sub-freezing conditions, water exists in soil pores in three forms: liquid water, water vapour and ice. The endothermic and exothermic processes are accompanied by phase changes. Here, the governing equations for coupled heat and mass transfer, namely, equations (3) and (12), are extended to include phase changes. The mass conservation is expressed as

$$
\begin{aligned}
\frac{\partial \theta}{\partial t} & =\frac{\partial \theta_{\mathrm{L}}}{\partial t}+\frac{\partial \theta_{\mathrm{v}}}{\partial t}+\frac{\rho_{\mathrm{i}}}{\rho_{\mathrm{w}}} \frac{\partial \theta_{\mathrm{i}}}{\partial t} \\
& =\frac{\partial}{\partial z}\left[K_{\mathrm{L} h}^{\prime}\left(\frac{\partial h}{\partial z}+1\right)+K_{\mathrm{L} T} \frac{\partial T}{\partial z}+K_{\mathrm{v} h} \frac{\partial h}{\partial z}+K_{\mathrm{v} T} \frac{\partial T}{\partial z}\right]
\end{aligned}
$$

where $\theta_{\mathrm{i}}$ is the pore ice content $\left(\mathrm{m}^{3} / \mathrm{m}^{3}\right)$; and $K_{\mathrm{L} h}^{\prime}$ is the permeability of unsaturated freezing soil and is different from the permeability of unsaturated soil $K_{\mathrm{L} h}(\mathrm{~m} / \mathrm{s})$. When the soil is frozen, the presence of ice in soil pores may significantly increase the resistance for liquid water flow, and lead to an apparent blocking effect. To account for the blocking effect, $K_{\mathrm{L} h}$ is usually reduced by multiplying a factor and thus results in the $K_{\mathrm{L} h}^{\prime}$. Taylor \& Luthin (1978) has investigated several relationships between $K_{\mathrm{L} h}^{\prime}$ and $K_{\mathrm{L} h}$ with measured data. Acceptable agreement was obtained when the following expression was used

$$
K_{\mathrm{L} h}^{\prime}=10^{-10 \theta_{\mathrm{i}}} K_{\mathrm{L} h}
$$

The adjusting parameter $10^{-10 \theta_{\mathrm{i}}}$ denotes the obstruction of pore ice to vapour flows. When the soil temperature is greater than $0^{\circ} \mathrm{C}, \theta_{\mathrm{i}}$ becomes zero, and $K_{\mathrm{L} h}^{\prime}$ reverts to $K_{\mathrm{L} h}$, as in equation (5).

The energy balance in an unsaturated freezing soil is described as follows

$$
\begin{aligned}
C_{\mathrm{p}} & \frac{\partial T}{\partial t}-L_{\mathrm{i}} \rho_{\mathrm{i}} \frac{\partial \theta_{\mathrm{i}}}{\partial t}+L_{\mathrm{w}} \rho_{\mathrm{w}} \frac{\partial \theta_{\mathrm{v}}}{\partial t} \\
= & \frac{\partial}{\partial z}\left[\lambda^{\prime}(\theta) \frac{\partial T}{\partial z}\right]-C_{\mathrm{L}} \frac{\partial q_{\mathrm{L}} T}{\partial z}-C_{\mathrm{v}} \frac{\partial q_{\mathrm{v}} T}{\partial z}-L_{\mathrm{w}} \rho_{\mathrm{w}} \frac{\partial q_{\mathrm{v}}}{\partial z}
\end{aligned}
$$


Table 3. Initial and boundary conditions for soil subjected to freezing

\begin{tabular}{|c|c|c|c|c|}
\hline Case & Initial water content: $\%$ & Temperature boundary & Water flow boundary & Depth of water table: $\mathrm{m}$ \\
\hline 3 & 7 & $\begin{array}{l}\text { Top: }-5^{\circ} \mathrm{C} ; \\
\text { Bottom: } 15^{\circ} \mathrm{C}\end{array}$ & $\begin{array}{l}\text { Top: covered } \\
\text { Bottom: water table }\end{array}$ & 20 \\
\hline 4 & 7 & $\begin{array}{l}\text { Top: }-5^{\circ} \mathrm{C} ; \\
\text { Bottom: } 15^{\circ} \mathrm{C}\end{array}$ & $\begin{array}{l}\text { Top: covered } \\
\text { Bottom: water table }\end{array}$ & 5 \\
\hline
\end{tabular}

The four terms on the right-hand side of equation (21) are the heat flow by conduction, the convection of sensible heat due to flowing water, the transfer of latent heat by vapour diffusion and the transfer of sensible heat by vapour diffusion, respectively. In equation $(21), L_{\mathrm{i}}$ is the latent heat of water freezing $\left(=334 \mathrm{~kJ} \mathrm{~kg}^{-1}\right) ; \lambda^{\prime}(\theta)$ is the heat conductivity of unsaturated freezing soil $((\mathrm{W} / \mathrm{m}) / \mathrm{K})$ and is obtained by replacing $\theta_{\mathrm{L}}$ of $\lambda(\theta)$ in equation (13) with $\theta_{\mathrm{L}}+F \theta_{\mathrm{i}}$ (Hansson et al., 2004), with $F$ being a dimensionless adjusting factor that accounts for the difference between the thermal conductivities of ice and liquid water, such that the ice content can affect the thermal conductivity under frozen conditions.

Concerning the movement of moisture and heat in the frozen zone, an additional constitutive relation is required to solve the governing equations. The generalised Clapeyron equation is used to establish the relationship between the pressure of unfrozen liquid water and that of pore ice when these two phases are in equilibrium (Harlan, 1973; Sheng et al., 2013, 2014). Substituting the Clapeyron equation into equation (4) leads to a relationship between the unfrozen liquid water content $\theta_{\mathrm{L}}$ and the soil temperature $T$

$$
\theta_{\mathrm{L}}=\left(\theta_{\mathrm{s}}-\theta_{\mathrm{r}}\right)\left[1+\left(-\alpha \frac{L_{\mathrm{i}} T}{\boldsymbol{g} T_{0}}\right)^{n}\right]^{-m}+\theta_{\mathrm{r}}
$$

where $T_{0}$ is the freezing point of water $(\mathrm{K})$; and $T$ in this equation is in units of ${ }^{\circ} \mathrm{C}$, such that a fully coupled model for moisture and heat transfer in unsaturated freezing soil is set up. In this model, $\theta_{\mathrm{L}}$ in the unfrozen zone solely relates to $h$ through the SWCC, as equation (4). $\theta_{\mathrm{v}}$ is a function of $\theta_{\mathrm{L}}, h$ and $T$ by equations (9) and (11). $\theta_{\mathrm{i}}$ relates to $T$ by a variable of unfrozen water content, which is a function of $T$ as equation (22), and $\theta_{\mathrm{i}}$ equals to total liquid water content minus unfrozen water content in the soil frozen zone.

\section{Numerical reproduction of canopy effect}

These governing equations (19) and (21) are solved with the assistance of Comsol Multiphysics (5.0) following the methods described in the earlier subsection 'Numerical implementation'. In an attempt to numerically reproduce the canopy effect, the proposed theory is applied to simulate the examples described in Table 3. A soil column with a height of $20 \mathrm{~m}$ or $5 \mathrm{~m}$ is subjected to a sub-zero temperature at its top and a temperature of $15^{\circ} \mathrm{C}$ at its bottom. The main difference between the soils in Table 2 and those in Table 3 is that the latter are subjected to freezing conditions. The top boundary of the soil is sealed against any water flux. The soil is the same as that used in the numerical study of the earlier subsection 'Numerical implementation', with properties shown in Fig. 2. The initial water content is $7 \%$, which is similar to the residual water content and represents an extremely dry condition. The computation period is 90 days.

Case 3 in Table 3 represents a deep groundwater table and is analysed first. Fig. 5 shows the computed profiles of the total volumetric water content $\left(\theta_{\mathrm{L}}+\theta_{\mathrm{v}}+\theta_{\mathrm{i}}\right)$, temperature, liquid water flux and vapour flux along the soil depth. Fig. 5(a) indicates that the water content near the lower end is significantly increased from the initial value, with capillary action occurring between 16 and $20 \mathrm{~m}$ at 90 days. The water content between 2.5 and $16 \mathrm{~m}$ remains close to the initial level. For the soil within the top $2.5 \mathrm{~m}$, the water content is significantly increased, especially for the soil at the top $1.0 \mathrm{~m}$, where a saturated water content of $42 \%$ is measured. Fig. 5(b) depicts the depths of the freezing front $\left(0^{\circ} \mathrm{C}\right.$ line $)$, which is located at approximately $0 \cdot 2,0.5$ and $0.8 \mathrm{~m}$ at 5,30 and 90 days, respectively. These positions coincide with the depths of maximum water content in Fig. 5(a). Moreover, Fig. 5(b) shows that the temperature profile below $8 \mathrm{~m}$ remains constant during the freezing period, which agrees with the field conditions in the Lanzhou area.

In Fig. 5(c), the positive value represents the upward flow of liquid water and negative downward. The positive value of the water flux between 16 and $20 \mathrm{~m}$ means that the liquid water in unsaturated soil migrates upwards under the capillary force, and the water content profile achieves an equilibrium state after a certain period. For the soil between 2.5 and $16 \mathrm{~m}$, minimal water flux is observed. The negative value of the water flux in the top $2.5 \mathrm{~m}$ of soil indicates a small downward liquid flow, which was caused by the downward flow of condensed water. This also implies that the increase in water content within the top region is not caused by the liquid water flow. The embedded chart in Fig. 5(c) shows that the liquid water flux is approximately zero within a top layer of soil $(0-0.2 \mathrm{~m}$ at 5 days, $0-0.5 \mathrm{~m}$ at 30 days and $0-0.8 \mathrm{~m}$ at 90 days), which corresponds to the frozen zone in the soil. Fig. 5(d) presents the computed results of the vapour flux and shows a clear upward flux near the surface zone. It can be concluded that water accumulation beneath the impervious surface is caused by vapour transfer. The vapour flux reaches a peak value at a certain depth, which is likely to be due to the vapour condensation and ice formation that occupy the soil pores and impede vapour transfer.

The water content and soil temperature at 0.5 and $1.0 \mathrm{~m}$ are monitored during the computation; the results are shown in Fig. 6. In Fig. 6(a), the soil temperatures at $0 \cdot 5$ and $1.0 \mathrm{~m}$ gradually decrease with time, with a decrease rate at $0.5 \mathrm{~m}$ that is greater than that at $1.0 \mathrm{~m}$. The temperature at $0.5 \mathrm{~m}$ reaches $0^{\circ} \mathrm{C}$ after 30 days, and the temperature at $1.0 \mathrm{~m}$ remains above $0^{\circ} \mathrm{C}$. In Fig. $6(\mathrm{~b})$, the total water content at $0.5 \mathrm{~m}$ shows a remarkable increase after approximately 10 days, experiences another obvious increase after approximately 30 days, and thereafter remains stable at $\sim 40 \%$. The reason for the two inflexion points is as follows. The temperature gradient in the soil is greater for the first 10 days, which results in a high vapour flux, leading to the first sudden increase in the total water content. The soil temperature at $0.5 \mathrm{~m}$ is approximately $0^{\circ} \mathrm{C}$ at 30 days (see Fig. 6(a)), and the freezing front tends to absorb more water, leading to the second sudden increase in the total water content. The soil at $1.0 \mathrm{~m}$ does not freeze and hence has only one sudden increase in its water content due to the larger temperature gradient during the initial 25 days (see Fig. 6(a)).

Case 4 is used to analyse the vapour flow in an unsaturated freezing soil with a shallow groundwater table. Fig. 7 shows 


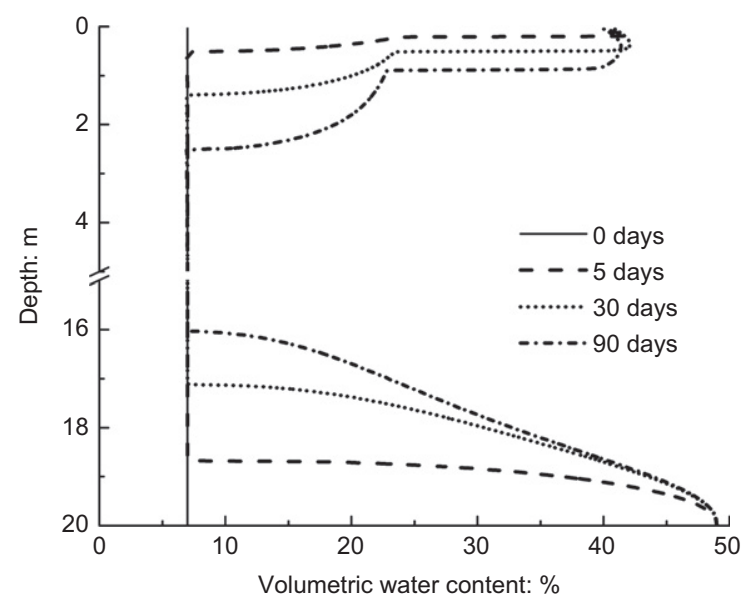

(a)

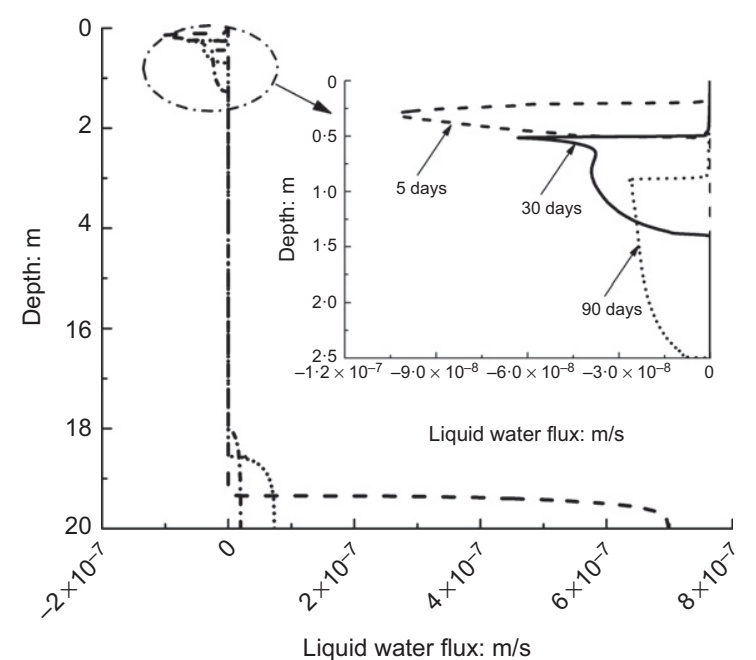

(c)

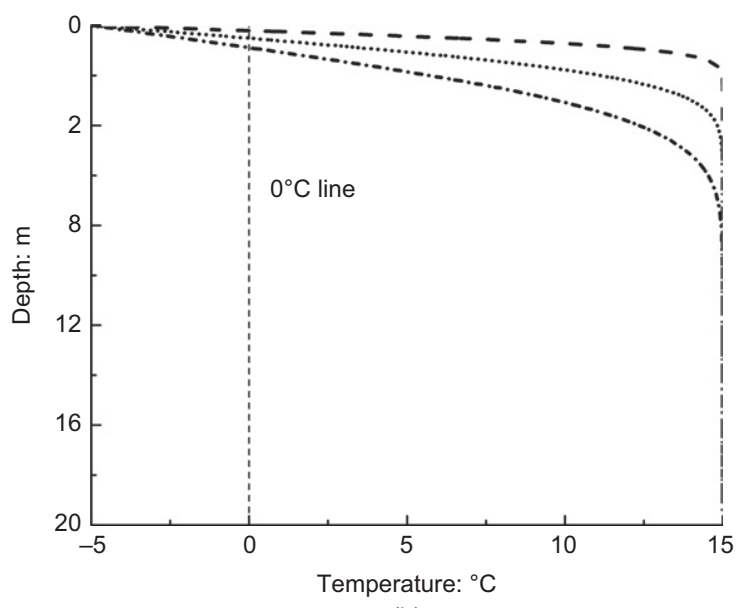

(b)

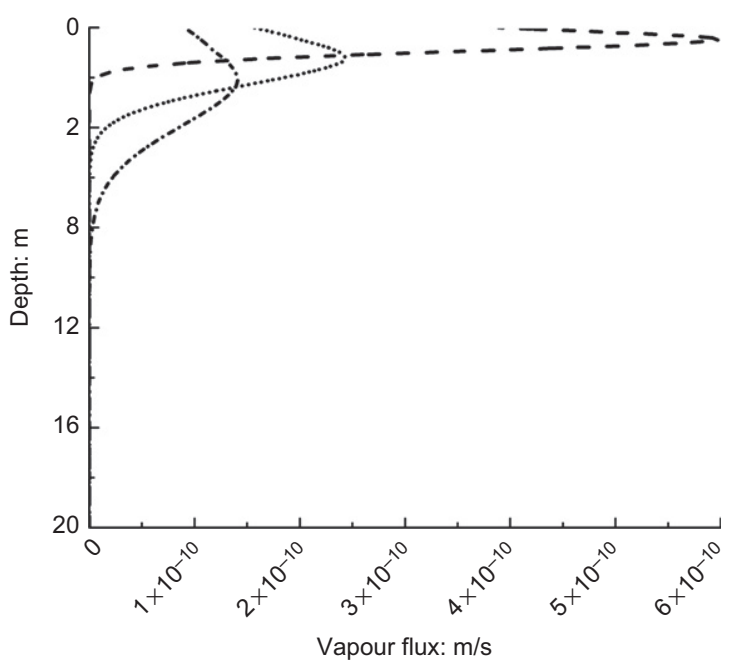

(d)

Fig. 5. (a) Computed total volumetric water content profile; (b) temperature profile; (c) liquid water flux profile; (d) vapour flux profile for case 3

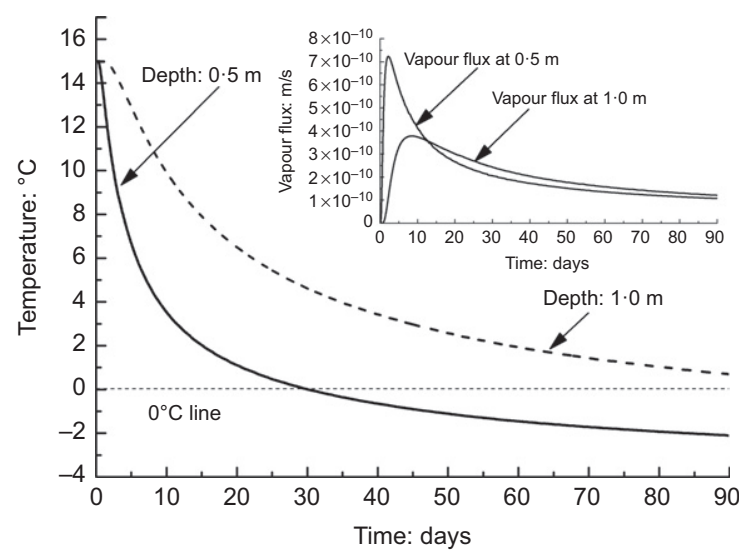

(a)

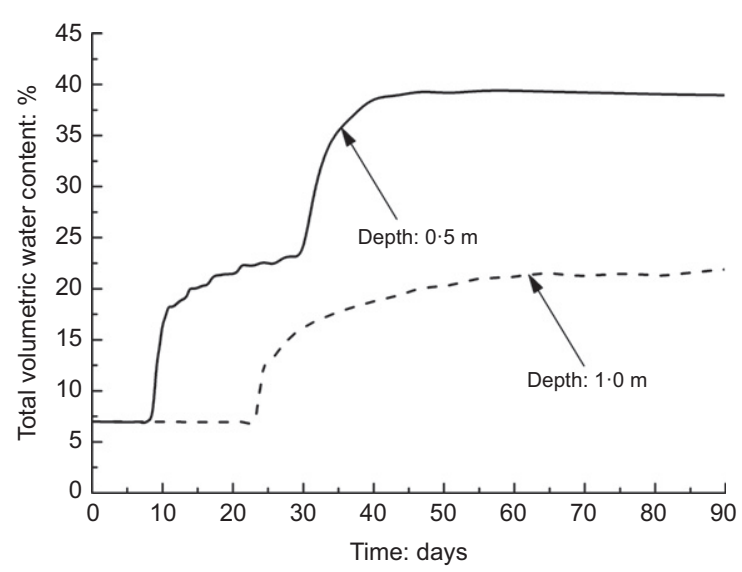

(b)

Fig. 6. (a) Computed temperatures and (b) total volumetric water contents at depths of $0.5 \mathrm{~m}$ and $1 \cdot 0 \mathrm{~m}$ plotted against elapsed time (the inset in (a) is the vapour flux at $0.5 \mathrm{~m}$ plotted against time)

the computed results for the total volumetric water content, temperature, liquid water flux and vapour flux along the soil depth. As depicted in Fig. 7(a), the capillary rises at 5 and 30 days are approximately 0.8 and $2.5 \mathrm{~m}$, respectively. Because the soil in the middle zone remains at the initial water content, the increase in the total water content in the top zone is mainly induced by vapour transfer. At 90 days, the capillary rise is greater than $4 \mathrm{~m}$, where it meets the freezing front (approximately $1.0 \mathrm{~m}$ from the top, as shown in Fig. 7(b)). The high capillary rise results in a large amount of water migrating towards the top surface and freezing there. Figs 7(c) and 7(d) show that the liquid flux in the top $1 \mathrm{~m}$ of the soil was negligible after the initial 30 days compared to the vapour flux. At 90 days, both the liquid flux and vapour 


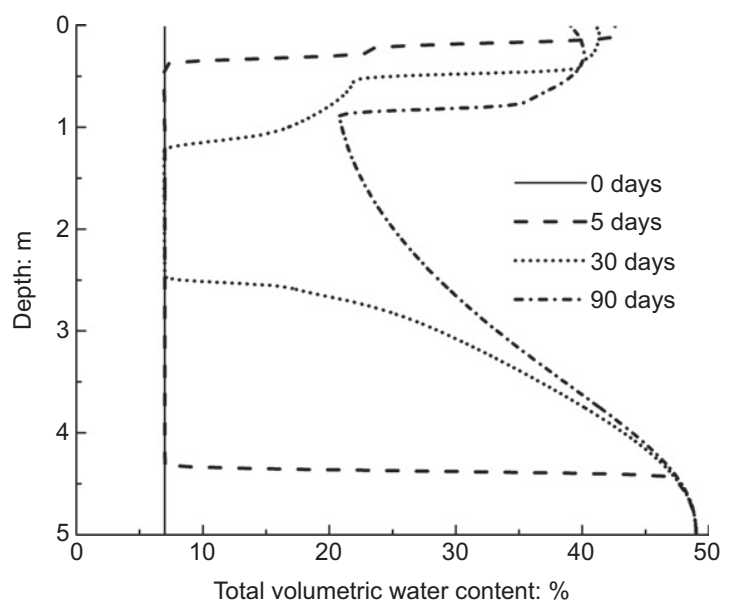

(a)

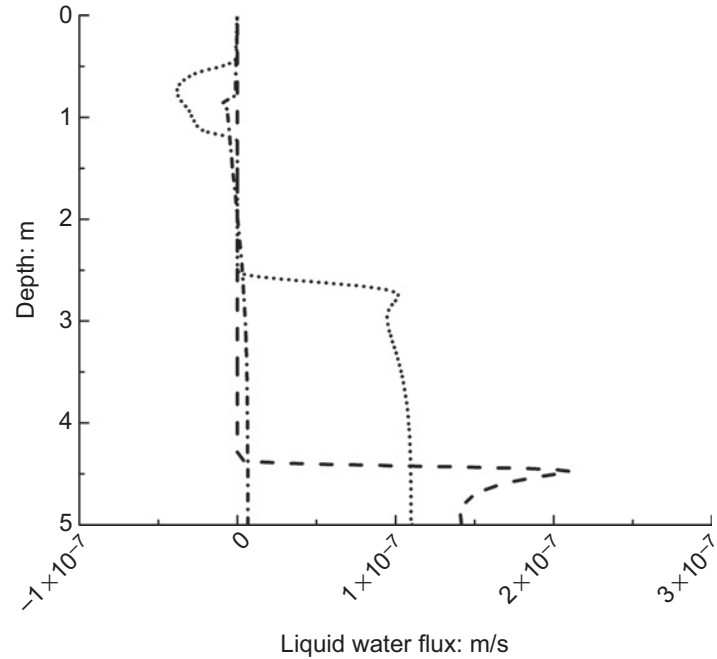

(c)

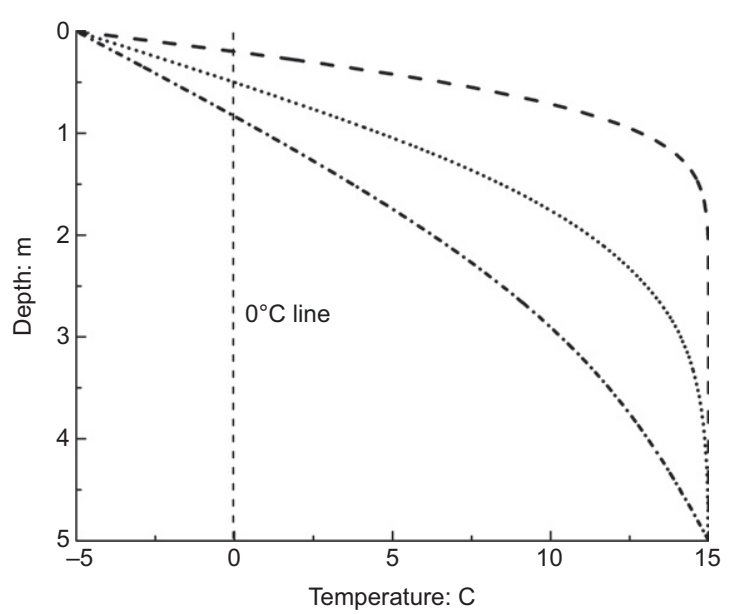

(b)

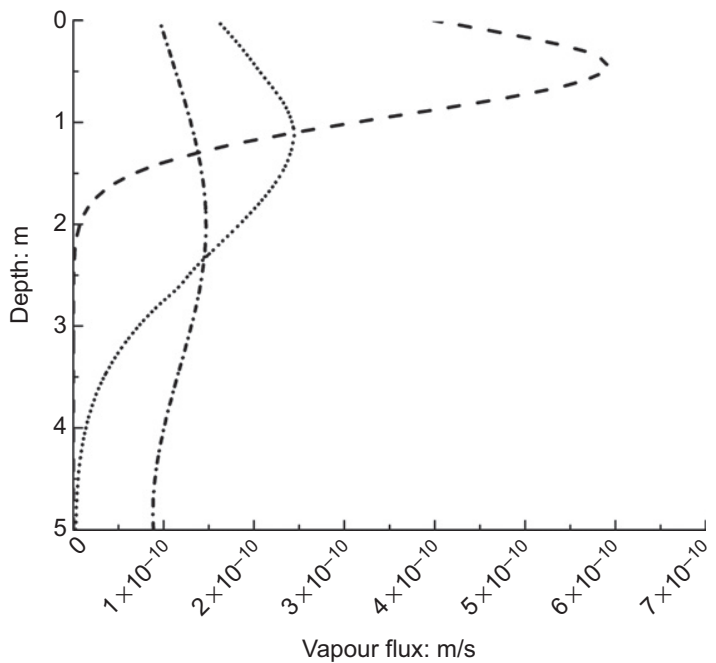

(d)

Fig. 7. (a) Computed total volumetric water content profile; (b) temperature profile; (c) liquid water flux profile; (d) vapour flux profile for case 4

flux achieved steady values along the soil column, and the liquid flux $\left(5 \times 10^{-9} \mathrm{~m} / \mathrm{s}\right)$ was greater than the vapour flux $\left(1 \times 10^{-10} \mathrm{~m} / \mathrm{s}\right)$. Therefore, before the capillary rise reaches the freezing front, the moisture accumulation is caused by the vapour flux in unsaturated freezing soil. Thereafter, the water content profile is controlled by the liquid water flow.

It is interesting to note that moisture would not accumulate in an unsaturated freezing soil that is exposed to the atmosphere. In this case, evaporation and sublimation at the ground surface prevent ice accumulation in the soil, a process analogous to the mechanism in a modern frost-free freezer. Inside such a freezer, air is circulated by one or more fans, and air circulation helps sublimate any ice or frost that may form in the freezer. Another example is the fact that wet clothes hung outside during cold winter days will first stiffen up owing to ice formation inside the clothes, but will eventually dry up owing to sublimation. Numerical simulation of an unsaturated freezing soil with an open top surface is difficult because the boundary conditions of evaporation and sublimation cannot be easily specified. However, field observations indicate that no ice forms in dry soils that are open to the atmosphere.

The canopy effect is reproduced in the numerical results in Figs 5, 6 and 7, which show that the canopy effect is an outcome of the interaction between vapour transfer in the unsaturated soil and ice formation in the freezing soil. The temperature gradient drives some moisture flow towards the top soil but is not sufficient to saturate the soil. The vapour-ice desublimation process plays the role of 'absorption' that drives the vapour towards the freezing zone. Soil freezing and the formation of ice increase the matric suction and decrease the vapour density, which in turn accelerate the upward vapour flow, leading to significant total moisture accumulation.

The model presented in this paper is one-dimensional only. In reality, vapour transfer in soil can occur in multiple directions. Humid air may enter the vapour-ice desublimation zone from horizontal directions, further enhancing the canopy effect.

\section{EXPERIMENTAL REPRODUCTION OF CANOPY EFFECT}

Test apparatus

To experimentally reproduce the canopy effect, a laboratory device was designed and patented at Central South University and is shown in Fig. 8. The design of the device is much based on the concepts discussed above. A soil specimen is placed in a polypropylene transparent cylinder $10 \mathrm{~cm}$ in diameter and $20 \mathrm{~cm}$ high. Two aluminium plates are installed at the top and base of the cylinder. The temperatures of the aluminium plates are controlled by circuiting oil to independent thermostats. The range of temperature control is from approximately $-30^{\circ} \mathrm{C}$ to $+90^{\circ} \mathrm{C}$, with an accuracy of $0 \cdot 1{ }^{\circ} \mathrm{C}$. 


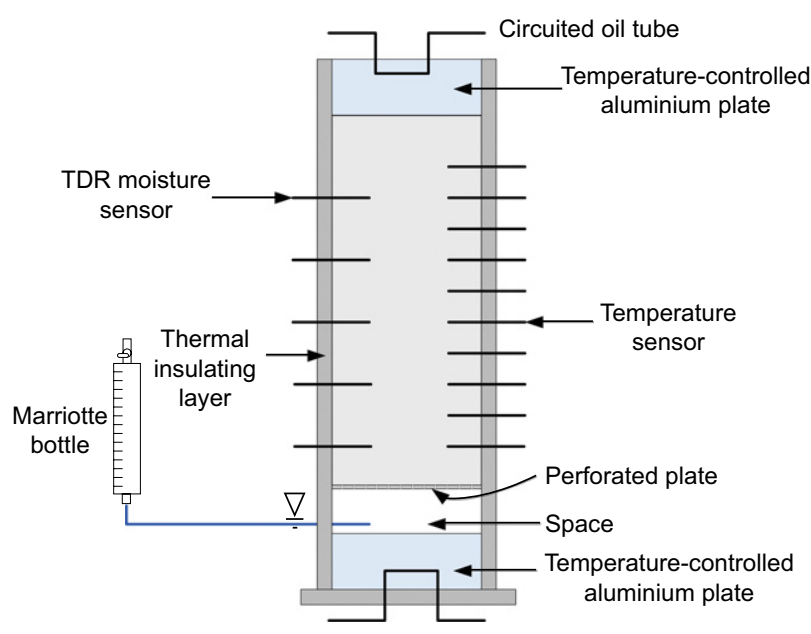

Fig. 8. Schematic diagram of test apparatus

The top end of the specimen is sealed against vapour and liquid flux with a plastic film. A 2-mm-thick perforated plate separates the soil specimen from the base aluminium plate, leaving a void approximately $3 \mathrm{~cm}$ high. Distilled water is supplied by a Mariotte bottle to the void, forming a 1-cm-deep water reservoir above the top surface of the base aluminium plate. The void between the water reservoir and the soil specimen ensures that only vapour is able to enter the specimen. To achieve unidirectional freezing of the specimen, the cylinder is insulated with organic cotton along the cylinder walls to minimise lateral heat transfer.

Moisture content and temperature along the specimen height are monitored using time-domain-reflectometer (TDR) transducers and thermistors, respectively. The entire device, including the data acquisition system and graphical display system, is then placed in a temperature-controllable chamber, as shown in Fig. 8. The bottom plate, the water reservoir and the chamber are usually subjected to the same (super-freezing) temperature, and the top plate is subjected to a different (usually sub-freezing) temperature. In a step freezing mode, the top plate temperature is fixed during the test, whereas in a ramped freezing mode, the top plate temperature is continuously decreased.

\section{Test procedure}

A calcareous sand is used in this study, with particle sizes varying in the range of $0.5 \mathrm{~mm}-1 \mathrm{~mm}$. A constant head test of the sand was conducted, thereby obtaining a hydraulic conductivity of $6 \cdot 11 \times 10^{-4} \mathrm{~cm} / \mathrm{s}$. The measured and simulated SWCCs of the calcareous sand are shown in Fig. 9. The oven-dry sample is first mixed with a certain amount of water to produce samples of different initial water contents. The sample is then packed into a sealed plastic bag and left at room temperature for $24 \mathrm{~h}$ until the moisture condition stabilises. Thereafter, the material is placed into the cylinder by lightly compacting layers approximately $2 \mathrm{~cm}$ thick. The final height of the sample is controlled at $13.5 \mathrm{~cm}$, with a dry density of $\sim 1.30 \mathrm{~g} / \mathrm{cm}^{3}$. During the process of packing samples, three water moisture probes and seven thermistors are inserted into the cylinder at certain depths. Temperatures and volumetric water contents are continuously measured throughout the testing period and recorded with an automatic data logger. In addition, water contents at different depths are checked before and after the completion of the test.

To reproduce and investigate the canopy effect, three conditions are applied, as shown in Table 4. Two initial gravity water contents are chosen, namely, $5 \%$ and $0 \%$,

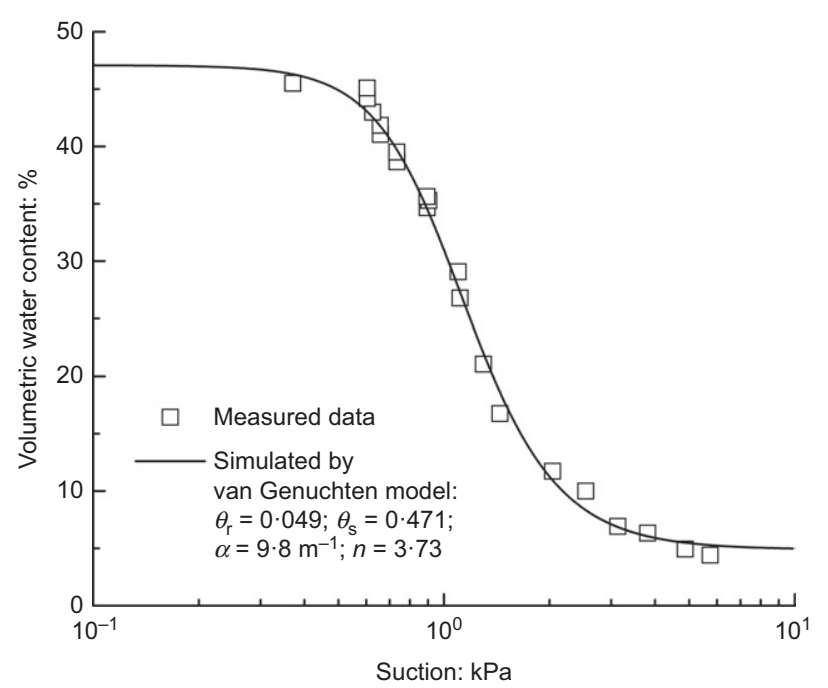

Fig. 9. Measured and simulated SWCCs of the sample. The symbols represent the measured data, and the solid line is the simulation results obtained by the van Genuchten (1980) model

corresponding to volumetric water contents of $6 \cdot 5 \%$ and $0 \%$, respectively. In the first two cases, the bottom and top temperatures are fixed over the entire testing period. In case 3 , the top temperature is decreased in steps, approximating a ramped freezing mode. For each case, the test duration is 7 days. The boundary temperatures in Table 4 are the setting values for the circulating fluids. They may differ from the actual temperatures at the specimen ends, due to the room temperature effect $\left(\sim 20^{\circ} \mathrm{C}\right.$ during the test $)$ and a small radial heat flux.

\section{Results and discussion}

Figure 10 shows the measured profile of the total volumetric water content at 7 days for cases 1,2 and 3. The tests are also simulated using the proposed model, and the simulation results are also shown in Fig. 10 for comparison. The computed results in Fig. 10 are fairly close to the measured values. In particular, the rapid increase in the total water content immediately below the impervious cover is well captured both in the experiments and in the numerical simulation. The measured and computed water contents exhibit minimal change at the bottom zone at $9 \mathrm{~cm}$ (Fig. 10(a)), $12 \mathrm{~cm}$ (Fig. 10(b)) and $10 \mathrm{~cm}$ (Fig. 10(c)) for cases 1, 2 and 3, respectively. An evident increase in water content is observed in the top zone of the soil column for all three cases. The experimental results seem to verify the $A_{2}$ canopy effect discussed in Fig. 1.

The measured and simulated temperature profiles for cases 1, 2 and 3 are presented in Fig. 11. A good agreement can be observed between the simulated and experimental values of the soil temperature at most times. The results also show that an approximately linear profile is obtained after approximately 1 day. The location of the freezing front is at approximately $10 \mathrm{~cm}$ for cases 1 and 2 after 1 day, and this location is at approximately $11 \mathrm{~cm}$ for case 3 after 4 days.

The water content profiles in Fig. 10 show a clear peak at the top boundary of the specimen. This peak water content represents the formation of clear ice between the soil specimen and the top aluminium plate. When the temperature is lower than the freezing point of water, the initial liquid water in the specimen will solidify into ice, and the suction at the ice-water interface will suck liquid water and vapour there to feed the growth of the ice. In case 2 where there is no initial liquid water in the soil, the vapour from below 
Table 4. Controlled parameters in the experiments

\begin{tabular}{l|c|c|c}
\hline Case & $\begin{array}{c}\text { Initial volumetric } \\
\text { water content }\end{array}$ & $\begin{array}{c}\text { Setting temperature at } \\
\text { bottom boundary: }{ }^{\circ} \mathrm{C}\end{array}$ & Setting temperature at top boundary: ${ }^{\circ} \mathrm{C}$ \\
\hline 1 & $6 \cdot 5$ & 10 & -10 \\
2 & 0 & 10 & -10 \\
3 & $6 \cdot 5$ & 10 & -3 (2 days), \\
& & & -6 (2 days), \\
& & & -10 (3 days) \\
\hline
\end{tabular}

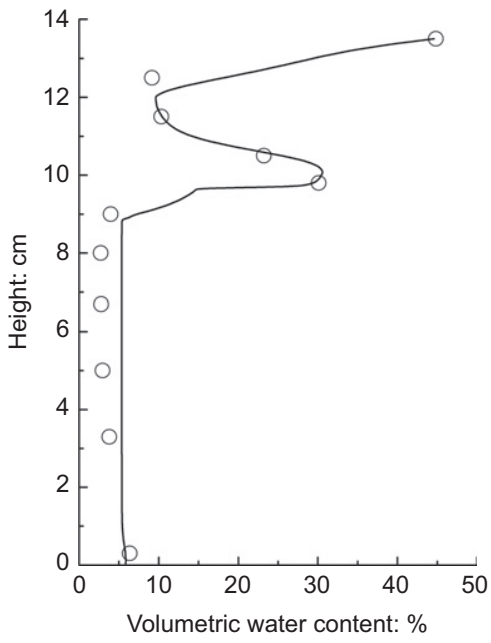

(a)

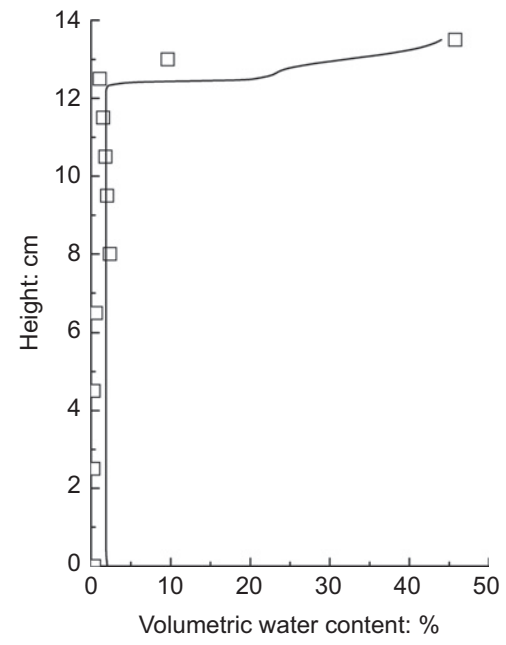

(b)

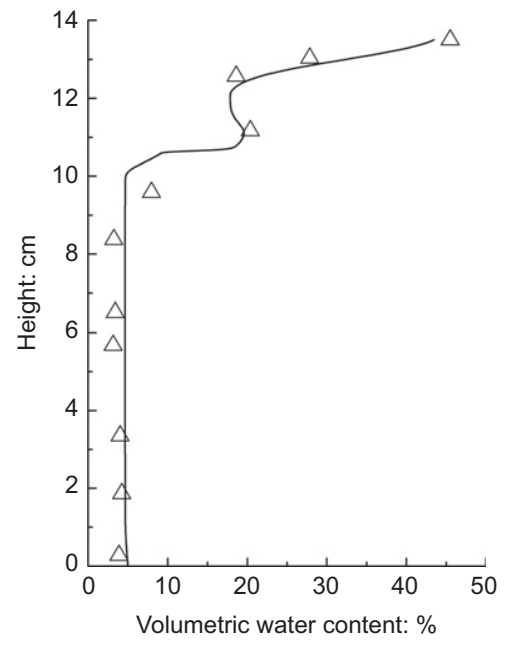

(c)

Fig. 10. Measured and simulated water content profiles at the ending times for: (a) case 1; (b) case 2; (c) case 3. The symbols represent the measured data and the solid lines represent the simulation results

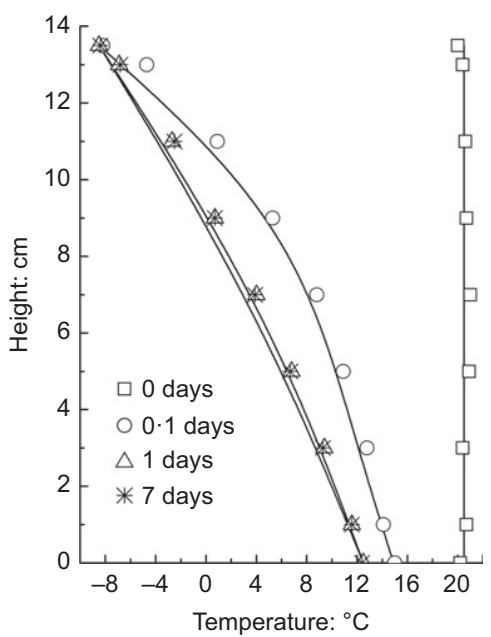

(a)

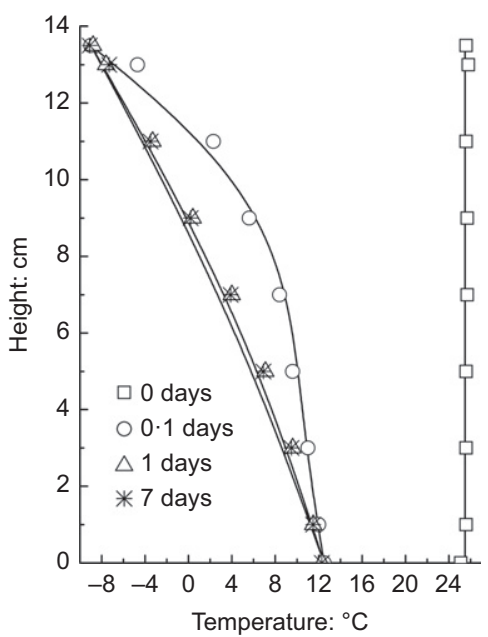

(b)

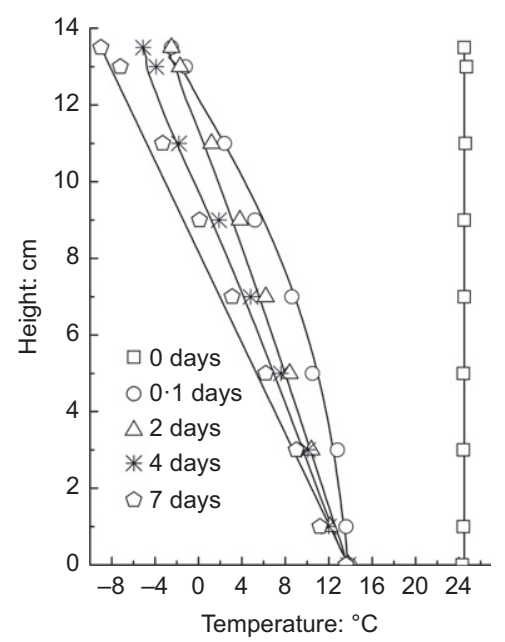

(c)

Fig. 11. Measured and simulated temperature profiles for: (a) case 1; (b) case 2; (c) case 3. The symbols represent the measured data and the solid lines represent the simulation results

will first condense into liquid water when it reaches the cold and impervious plate, and then change into ice directly through desublimation. The photographs taken at the end of the experiment show that a clear ice lens exists between the aluminium plate and the soil specimen (see Fig. 12). As the temperature continues to drop in the soil, the freezing front continues to penetrate into the specimen and pore ice starts to appear in the soil behind the freezing front, first through solidification of liquid water and then through desublimation of vapour. The formation of pore ice in the soil will reduce the permeability of the soil to vapour and liquid water.
When the freezing front finally stabilises, sufficient pore ice will accumulate somewhere in the soil behind the freezing front, reducing the amount of vapour transfer towards the impervious plate, and forming a new ice-rich layer in the soil. This ice-rich layer corresponds to the second peak in the water content profiles for case 1 and case 3 . The second peak for case 3 is less pronounced because it takes longer for the freezing front to stabilise in a ramped freezing mode. For case 2 , the soil is oven-dried. The zero initial water content leads to little pore ice in the soil and the vapour can continue all the way to the impervious plate. 


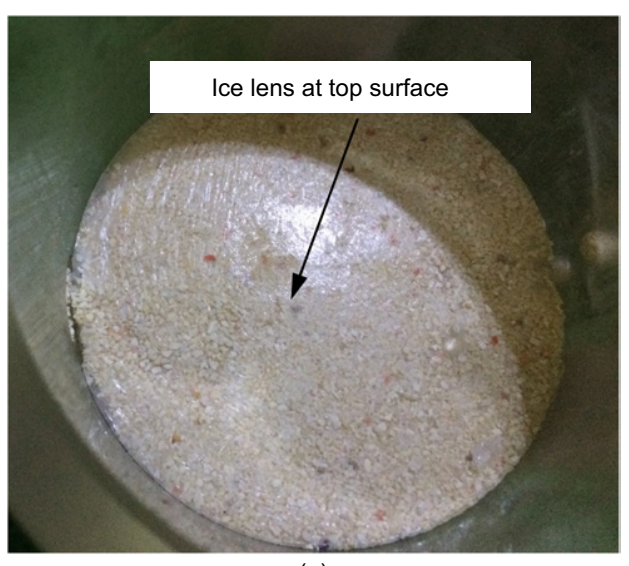

(a)

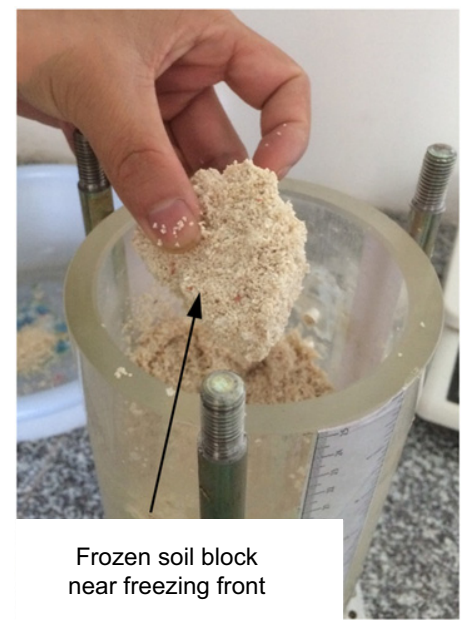

(c)

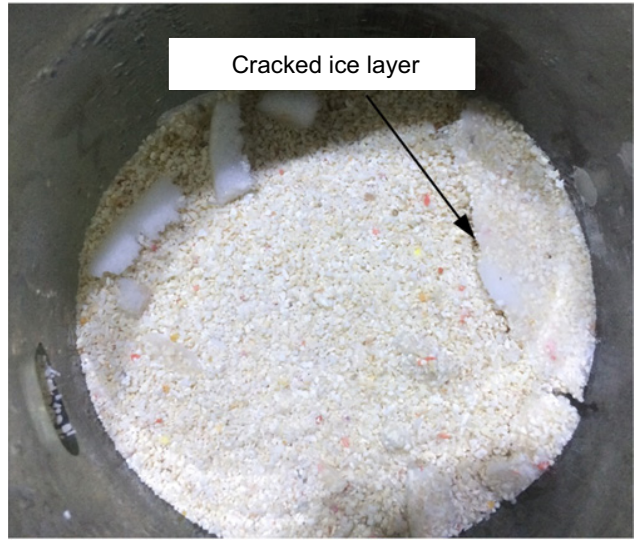

(b)

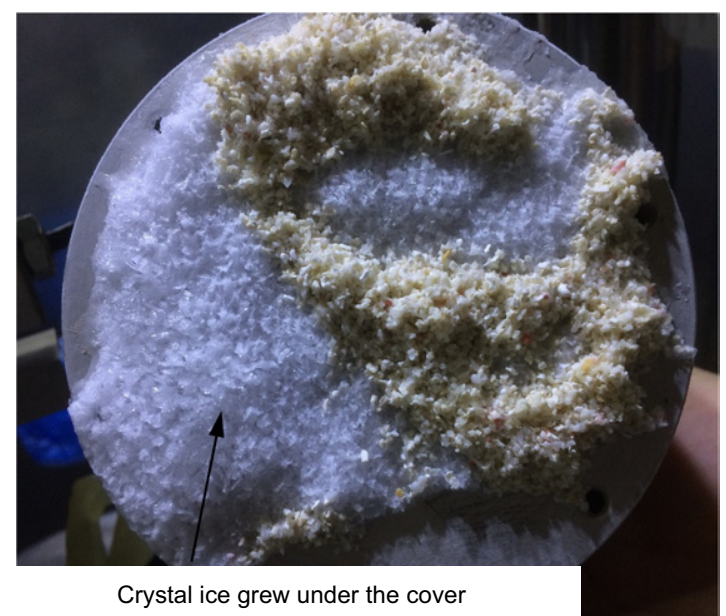

(d)

Fig. 12. Ice accumulated under the impervious cover: (a) a mirror-like soil surface caused by high ice content; (b) a cracked ice layer with a thickness of approximately $0.5 \mathrm{~cm}$; (c) hardened soil block near the freezing front; (d) crystal ice growing under the impervious cover; the thickness was approximately $0.5 \mathrm{~cm}$ at 7 days

In the numerical simulation, the formation of new ice lenses in the freezing soil is not considered. However, the model seems to be able to predict a peak vapour flux in the frozen fringe, due to the balance between the vapour permeability, temperature and suction, see Fig. 5. This peak vapour flux is the reason for the second peak in the water content profiles for case 1 and case 3 .

Some visual evidence of ice formation in the frozen soil is shown in Fig. 12. It can be observed that a large amount of ice is formed and accumulated immediately beneath the cover (Fig. 12(a)). The mirror-like soil surface shown in Fig. 12(a) is a clear indication of high ice content. The thickness of the ice-rich layer is approximately $0.5 \mathrm{~cm}$ (Fig. 12(b)). Fig. 12(c) depicts a hardened soil block near the position of the freezing front, where the ice provides a cohesive force and leads to the agglomeration of soil particles. Fig. 12(d) shows the morphology of crystal ice under the impervious cover. The thickness of the ice accumulated at that location is approximately $0.5 \mathrm{~cm}$ after 7 days and would continue to grow if sufficient vapour was provided from below. The results clearly show that soil freezing fed by vapour transfer can result in a total water content close to full saturation, which is the experimental reproduction of the $\mathrm{A}_{2}$ type of canopy effect.

\section{CONCLUSIONS}

The role of vapour flow is usually ignored when analysing water migration in unsaturated soils. Indeed, vapour flow is seldom considered in geotechnical design. However, there are circumstances wherein vapour transfer can lead to severe engineering problems and must be considered. One such circumstance is moisture accumulation caused by vapour transfer under impervious covers and is referred to as the canopy effect. It has been reported that significant moisture can accumulate in unsaturated freezing soils, leading to frost damage in airport runways and road pavements.

Models based on the Philip \& de Vries (1957) theory of coupled heat and mass transfer in unsaturated soils are incapable of capturing a significant canopy effect. This is because moisture flow driven by temperature gradients in unsaturated soils will be balanced by that driven by the suction gradient.

A new approach to modelling the coupled movements of moisture and heat in unsaturated freezing soils is presented in this paper, in which phase changes during evaporation, condensation and desublimation are considered. The numerical results demonstrate that soil freezing fed by vapour transfer can indeed produce a water content close to full saturation for soil under an impervious cover.

A laboratory device is specially designed to investigate vapour transfer in unsaturated freezing soils. Experimental verifications show that the proposed model can predict the variations in water content and soil temperature reasonably well. Moreover, the test results show that vapour transfer in unsaturated freezing soil can lead to significant moisture and ice accumulation near the freezing end of soil specimens 
and provide solid experimental justification for the proposed canopy effect.

\section{ACKNOWLEDGEMENTS}

This research was supported by the National Basic Research Program of China (no. 2014CB047001), National Natural Science Foundation of China (no. 51508578) and Project of Innovation-driven Plan of Central South University (no. 2015CX018).

\section{CONTRIBUTIONS TO THE PAPER}

S. Zhang proposed the concept of moisture accumulation caused by vapour transfer, and designed the experimental device and the testing programme. J. Teng developed the numerical model, oversaw the numerical analyses and laboratory tests, and drafted the first version of the manuscript. $\mathrm{Z}$. He and Y. Liu were responsible for the computer implementation and conducted the numerical analyses. Z. He, S. Liang and Y. Liu were responsible for manufacturing the experimental apparatus and conducted the laboratory tests. Y. Yao was the leader for the research programme funded by the Ministry of Science and Technology (2014CB47000). D. Sheng was the leader of the research team and oversaw the progress of the whole research programme. He also proposed the conceptual model of the canopy effect (vapour transfer enhanced by vapour-ice desublimation), designed the structure of the paper and helped in drafting the manuscript. J. Teng and D. Sheng drafted the revision of the manuscript after review, and the revision was agreed by the other authors.

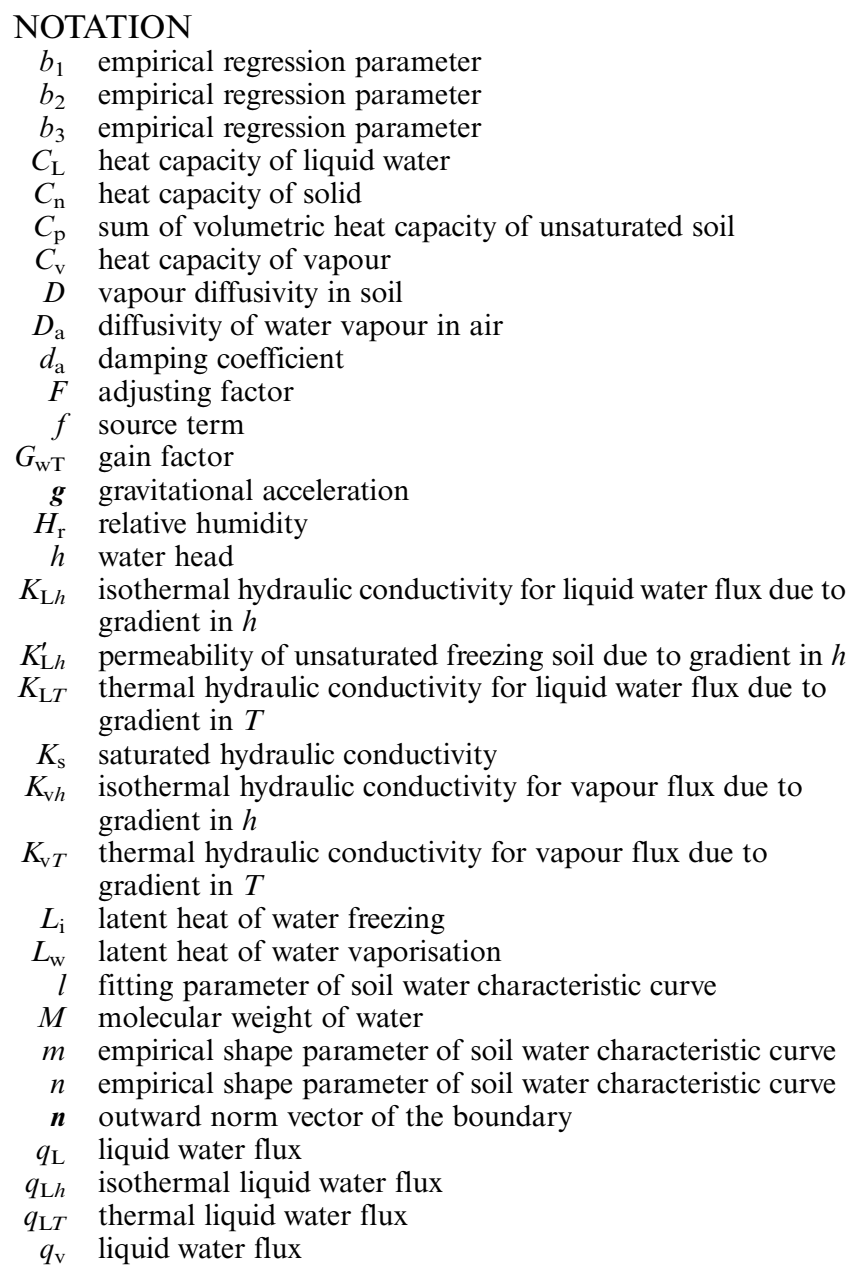

$q_{\mathrm{v} h}$ isothermal vapour flux

$q_{\mathrm{v} T}$ thermal vapour flux

$R$ universal gas constant

$T$ temperature

$T_{0} \quad$ freezing point of water

$z$ spatial coordinate positive upward

$\alpha$ empirical shape parameter of soil water characteristic curve

$\boldsymbol{\Gamma}$ flux vector

$\gamma$ surface tension of soil water

$\gamma_{0} \quad$ surface tension of soil water at $25^{\circ} \mathrm{C}$

$\eta$ enhancement factor

$\Theta$ effective saturation

$\theta$ total water content

$\theta_{\text {a }} \quad$ air-filled porosity

$\theta_{\mathrm{i}}$ pore ice content

$\theta_{\mathrm{L}} \quad$ liquid water content

$\theta_{\mathrm{r}}$ residual water content

$\theta_{\mathrm{s}} \quad$ saturated water content

$\theta_{\mathrm{v}}$ equivalent vapour content

$\kappa$ primary variable in governing equations

$\bar{\kappa} \quad$ virtual primary variable

$\lambda(\theta) \quad$ soil thermal conductivity

$\lambda^{\prime}(\theta)$ heat conductivity of unsaturated freezing soil

$\rho_{\mathrm{vs}} \quad$ saturated vapour density

$\rho_{\mathrm{w}} \quad$ liquid water density

$\tau$ tortuosity factor

$\Omega$ domain of interest

\section{REFERENCES}

Blight, G. E. (1971). Flow of air through soils. Soil Mech. Found. Engng Div., ASCE 97, No. 11, 607-624.

Campbell, G. S. (1985). Soil physics with BASIC. New York, NY, USA: Elsevier.

Cass, A., Campbell, G. S. \& Jones, T. L. (1984). Enhancement of thermal water vapor diffusion in soil. Soil Sci. Soc. Am. J. 48, No. 1, 25-32.

Chung, S. \& Horton, R. (1987). Soil heat and water flow with a partial surface mulch. Water Resources Res. 23, No. 12, $2175-2186$.

Cui, Y. J., Gao, Y. B. \& Ferber, V. (2010). Simulating the water content and temperature changes in an experimental embankment using meteorological data. Engng Geol. 114, No. 3-4, 456-471.

de Vries, D. A. (1958). Simultaneous transfer of heat and moisture in porous media. Trans. Am. Geophys. Union 39, No. 5, 909-916.

Eigenbrod, K. \& Kennepohl, G. (1996). Moisture accumulation and pore water pressures at base of pavements. Transpn Res. Rec. 1546, 151-161.

Fredlund, D. G. \& Rahardjo, H. (1993). Soil mechanics for unsaturated soils. New York, NY, USA: John Wiley and Sons, Inc.

Guthrie, W., Hermansson, Å. \& Woffinden, K. (2006). Saturation of granular base material due to water vapor flow during freezing: laboratory experimentation and numerical modeling. Cold Regions Engng 29, No. 11, 1-12.

Guymon, G. L. \& Luthin, J. N. (1974). A coupled heat and moisture transport model for Arctic soils. Water Resources Res. 10, No. 5, 995-1001.

Hansson, K., Šimůnek, J., Mizoguchi, M., Lundin, L. C. \& van Genuchten, M. T. (2004). Water flow and heat transport in frozen soil: numerical solution and freeze-thaw applications. Vadose Zone J. 3, No. 2, 527-533.

Harlan, R. L. (1973). Analysis of coupled heat-fluid transport in partially frozen soil. Water Resources Res. 9, No. 5, 1314-1323.

Hillel, D. (1971). Soil and water: physical principles and processes. New York, NY, USA: Academic Press.

Hu, H., Yang, S. \& Lei, Z. (1992). A numerical simulation for heat and moisture transfer during soil freezing. J. Hydraul. Engng 7, No. 6, 1-8 (in Chinese).

Konrad, J. M. \& Morgenstern, N. R. (1981). The segregation potential of a freezing soil. Can. Geotech. J. 18, No. 4, 482-491.

Kung, S. K. J. \& Steenhuis, T. S. (1986). Heat and moisture transfer in a partly frozen nonheaving soil. Soil Sci. Soc. Am. J. 50, No. $5,1114-1122$. 
Li, Q., Yao, Y. P., Han, L. M., Hu, J., Peng, R. \& Wang, N. D. (2014). Pot-cover effect of soil. Ind. Constr. 44, No. 2, 68-71 (in Chinese with English abstract).

Miller, R. D. (1978). Frost heaving in non-colloidal soils. In Proceedings of the 3rd international conference on permafrost, Edmonton, Alberta, pp. 708-713. Ottawa, ON, Canada: National Research Council of Canada.

Milly, P. C. D. (1984). A simulation analysis of thermal effects on evaporation from soil. Water Resources Res. 20, No. 8, 1087-1098.

Mualem, Y. (1976). A new model for predicting the hydraulic conductivity of unsaturated porous media. Water Resources Res. 12, No. 3, 513-522.

Nassar, I. N. \& Horton, R. (1989). Water transport in unsaturated nonisothermal salty soil: II. Theoretical development. Soil Sci. Soc. Am. J. 53, No. 5, 1330-1337.

Nassar, I. N. \& Horton, R. (1992). Simultaneous transfer of heat, water, and solute in porous media: I. Theoretical development. Soil Sci. Soc. Am. J. 56, No. 5, 1350-1356.

Or, D., Lehmann, P., Shahraeeni, E. \& Shokri, N. (2013). Advances in soil evaporation physics - a review. Vadose Zone J. 12, No. 4.

Philip, J. R. \& de Vries, D. A. (1957). Moisture movement in porous materials under temperature gradients. Trans. Am. Geophys. Union 38, No. 2, 222-232.

Saito, H., Śimůnek, J. \& Mohanty, B. P. (2006). Numerical analysis of coupled water, vapor, and heat transport in the vadose zone. Vadose Zone J. 5, No. 2, 784-800.

Sakai, M., Toride, N. \& S Simůnek, J. (2009). Water and vapor movement with condensation and evaporation in a sandy column. Soil Sci. Soc. Am. J. 73, No. 3, 707-717.

Sheng, D., Zhang, S., Yu, Z. \& Zhang, J. (2013). Assessing frost susceptibility of soils using PCHeave. Cold Region Sci. Technol. 95, No. 11, 27-38.

Sheng, D., Zhang, S., Niu, F. \& Cheng, G. (2014). A potential new frost heave mechanism in high-speed railway embankments. Géotechnique 64, No. 2, 144-154, http://dx.doi.org/10.1680/ geot.13.P.042.

Šimůnek, J., Šejna, M., Saito, H., Sakai, M. \& van Genuchten, M. T. (2013). The HYDRUS-1D software package for simulating the movement of water, heat, and multiple solutes in variably saturated media. Version 4.17. HYDRUS softw. ser. 3. Riverside, CA, USA: Department of Environmental Science, University of California.

Taylor, G. S. \& Luthin, J. N. (1978). A model for coupled heat and moisture transfer during soil freezing. Can. Geotech. J. 15, No. 4, 548-555.

Teng, J., Yasufuku, N., Liu, Q. \& Liu, S. (2013). Analytical solution for soil water redistribution during evaporation process. Water Sci. Technol. 68, No. 12, 2545-2551.

Teng, J., Sheng, D., Liang, S. \& Zhang, S. (2015). A numerical model for heat and moisture transfer in unsaturated freezing soil. In Unsaturated soil mechanics - from theory to practice: proceedings of the 6th Asia Pacific conference on unsaturated soils, Guilin, China (eds Z. Chen, C. Wei, D. Sun and X. Xu), pp. 629-634. London, UK: CRC Press, Taylor \& Francis Group.

Teng, J., Yasufuku, N., Zhang, S. \& He, Y. (2016). Modelling water content redistribution during evaporation from sandy soil in presence of water table. Comput. Geotech. 75, No. 5, 210-224.

van Genuchten, M. T. (1980). A closed-form equation for predicting the hydraulic conductivity of unsaturated soils. Soil Sci. Soc. Am. J. 44, No. 5, 892-898.

Wilson, G. W., Fredlund, D. G. \& Barbour, S. L. (1994). Coupled soil-atmosphere modelling for soil evaporation. Can. Geotech. J. 31, No. 2, 151-161.

Zeng, Y., Su, Z., Wan, L. \& Wen, J. (2011). Numerical analysis of air-water-heat flow in unsaturated soil: Is it necessary to consider airflow in land surface models? J. Geophys. Res. 116, No. D20, D20107.

Zhang, S., Sheng, D., Zhao, G., Niu, F. \& He, Z. (2016a). Analysis of frost heave mechanisms in a high-speed railway embankment. Can. Geotech. J. 53, No. 3, 520-529.

Zhang, S., Teng, J., He, Z. \& Sheng, D. (2016b). Importance of vapor flow in unsaturated freezing soil: a numerical study. Cold Regions Sci. Technol. 126, 1-9.

Zhou, J., Wei, C., Li, D. \& Wei, H. (2014). A moving-pump model for water migration in unsaturated freezing soil. Cold Regions Sci. Technol. 104-105, 14-22. 